\title{
Multiobjective Route Planning Model and Algorithm for Emergency Management
}

\author{
Wen-mei Gai, ${ }^{1,2}$ Zhong-an Jiang, ${ }^{1}$ Yun-feng Deng, ${ }^{2}$ Jing Li, ${ }^{3}$ and Yan Du ${ }^{1}$ \\ ${ }^{1}$ School of Civil and Environmental Engineering, University of Science and Technology Beijing, Beijing 100083, China \\ ${ }^{2}$ Chinese Academy of Governance, Beijing 100089, China \\ ${ }^{3}$ Institute of Public Safety, China Academy of Safety Science and Technology, Beijing 100012, China
}

Correspondence should be addressed to Zhong-an Jiang; jza1963@263.net

Received 4 October 2014; Revised 5 December 2014; Accepted 8 December 2014

Academic Editor: Erik Cuevas

Copyright (C) 2015 Wen-mei Gai et al. This is an open access article distributed under the Creative Commons Attribution License, which permits unrestricted use, distribution, and reproduction in any medium, provided the original work is properly cited.

\begin{abstract}
In order to model route planning problem for emergency logistics management taking both route timeliness and safety into account, a multiobjective mathematical model is proposed based on the theories of bounded rationality. The route safety is modeled as the product of safety through arcs included in the path. For solving this model, we convert the multiobjective optimization problem into its equivalent deterministic form. We take uncertainty of the weight coefficient for each objective function in actual multiobjective optimization into account. Finally, we develop an easy-to-implement heuristic in order to gain an efficient and feasible solution and its corresponding appropriate vector of weight coefficients quickly. Simulation results show the effectiveness and feasibility of the models and algorithms presented in this paper.
\end{abstract}

\section{Introduction}

In recent years, a number of frequent natural disasters and man-made catastrophic events happen occasionally [1-3]. As an emerging research area, emergency logistics management is attracting more and more attention of researchers [48]. Disaster relief requires efforts on many fronts: providing rescue, health and medical assistance, water, food, shelter, and long-term recovery efforts. Much of successful and rapid relief relies on the logistical operations of supply delivery $[9,10]$. Furthermore, important or hazardous materials must be transferred from the affected areas to safety areas; even those people at risk in some disasters like gas leak and fire also should be evacuated from the affected areas to safety areas. Many of successful and rapid evacuation and transfer tasks rely on the effective emergency logistics operations.

Route planning is one of the fundamental problems in emergency logistics management. Among the existing researches of emergency logistics management [11-14], several complicated models have been built considering the disaster conditions. But most of the existing research works of emergency logistics management took time as the most important factor in route planning to be considered. The objective of the existing route planning model was to minimize the time needed to complete the logistics transmission process. However, the route safety should also be taken into account as an objective of the route planning model for emergency logistics management considering the vulnerability of humans during disaster time.

On the other hand, most of them consider the parameters on each arc of the logistics network as constants. In fact, the travel conditions on the arcs will be greatly affected by disaster extension especially under some disasters like hurricane, flood, and gas leak that will extend gradually in time and space $[15,16]$. For example, the degree of congestion on each arc will be dynamic under disaster conditions, which will make the travel speed on each arc change correspondingly, and the safety through each arc may also change under disaster conditions. Furthermore, the change extent will differ with the positions of the arcs and the severity of the disaster.

Yuan and Wang [15] constructed a model to express the effect that the disaster extension influenced the travel speed. Moreover, they built a multiobjective model taking more actual factors into account. To the best of our knowledge, it is 
necessary for us to go on the research towards this direction. Zhang et al. [16] proposed a novel bioinspired method to solve the selection model for emergency logistics management under real-time effect of disaster extension. Both of them first convert two objective functions into a single-objective function by using the weighted-sum method and assume the weighting coefficients as fixed real numbers. However, due to the complexity of actual problems and subjectivity as well as limitations of decision-makers' cognition, decision-makers often encounter a lot of uncertainties so that they can only get variation ranges of the weighting coefficients $[17,18]$. This uncertainty will give decision-makers a great deal of difficulty in emergency decision-making.

In this paper, we focus on the route planning problem in emergency logistics management and build a mathematical model to select the optimal route. The motivation of this research is to consider more actual factors in time of disaster and decision-making when building models and designing algorithms. The factors we take into account include travel time and the safety of the route, as well as uncertainty of the weight coefficient for each objective function in actual multiobjective optimization. The safety of the path is modeled as the product of safety through arcs included in the path. A multiobjective mathematical model is built in our study and algorithms are developed to solve the model. Our method for studying path selection problem in emergency logistics management is presented in Figure 1.

As described in Figure 1, firstly, a multiobjective mathematical model based on the theories of bounded rationality is built for route planning in emergency logistics management considering route timeliness and safety. The two objectives of the model are to minimize total travel time along the route and to maximize the safety of the route, respectively. We proposed an easy-to-implement heuristic method in order to gain an efficient and feasible solution quickly. In our method, we first translate (6) into (9) and then the proposed model can be converted into a conditional multiobjective shortest path model which is different from classical shortest path problem. To solve this problem, the weighted-sum method is used to convert the conditional multiobjective shortest path problem into a single-objective shortest path problem and two constraints, where we take uncertainty of the weight coefficient for each objective function in actual multiobjective optimization into account. Based on the single-objective shortest path model, we can construct two auxiliary functions. Finally, the main-objective method is used to define the optimal solution of the multiobjective route planning model. By this way, two different heuristic algorithms are designed to solve the proposed model. In the static heuristic algorithm, an efficient and feasible solution and its corresponding appropriate vector of weight coefficients for the multiobjective route planning model can be obtained quickly by using the classical Dijkstra algorithm and $A^{*}$ algorithm based on the established auxiliary functions if not considering real-time effect of disaster extension, and, in the dynamic heuristic algorithm, an efficient and feasible solution and its corresponding appropriate vector of weight coefficients for the multiobjective route planning model can be acquired by using the modified Dijkstra algorithm and $D^{*}$ algorithm based on the established auxiliary functions if considering real-time effect of disaster extension. Simulation results show the effectiveness and feasibility of the model and algorithm.

This short communication is organized as follows. Section 2 gives the multiobjective route planning model for emergency logistics management. Section 3 introduces preliminaries briefly. Section 4 details the proposed method to solve route planning problem in static and dynamic environments, respectively. Section 5 shows the simulation results in different cases to illustrate the efficiency of the proposed method. Section 6 ends the communication with conclusion.

\section{Route Planning Model for Emergency Logistics Management}

2.1. Definition of Variables and Parameters. (1) Let arcs denote the ground roads and nodes denote road intersections. An emergency logistics network is defined by a graph $G=(V, E)$, where $V=\left\{v_{1}, v_{2}, \ldots, v_{n}\right\}$ is the set of nodes and $E \subseteq V \times V$ is the set of arcs. $v_{1}, v_{2}, \ldots, v_{n}$ denote the nodes in the network.

(2) $l_{i j}$ denotes the length of the arcs between nodes $v_{i}$ and $v_{j}$, where $\left(v_{i}, v_{j}\right) \in E$.

(3) $t_{i j}, s_{i j}$ denote the travel time and route safety from node $v_{i}$ to $v_{j}$, respectively. Let $t_{i}$ denote the time when the logistics reach node $v_{i}$ and $t_{j}$ denote the time when the logistics reach node $v_{j}$ along arc $\left(v_{i}, v_{j}\right)$. It is obvious that $t_{i j}=t_{j}-t_{i}$.

(4) $u_{0 i j}$ is the travel speed on $\operatorname{arc}\left(v_{i}, v_{j}\right)$ under free travelling conditions. Define $u_{i j}(t)$ as the travel speed on arc $\left(v_{i}, v_{j}\right)$ in the affected area at time $t$ under disaster conditions.

Observing the extension processes of some disasters such as flood and hurricane, we can find that the travel speed on each arc of the network will differ with the extension of disasters [15]. Hence, we use a congestion coefficient $\xi_{i j}$ to denote the change extent of the travel speed, which is affected by the position of the arc, the type of the disaster, and so forth. Then $u_{i j}(t)=\xi_{i j} \cdot u_{0 i j}$. Based on the above definitions, it can be acquired that

$$
\int_{t_{i}}^{t_{j}} u_{i j}(t) d t=l_{i j}, \quad 0<i \leq j<n .
$$

The congestion coefficient on each arc of the logistics network $\xi_{i j}$ can be considered as a fixed value when the period of logistics operation is short, namely, in a static environment. But when the period of logistics operation is long, $\xi_{i j}$ may dynamically change with the extension of disasters in time, and the route planning problem we focus on is actually a shortest path problem in a dynamic environment.

(5) $x_{i j}$ is the decision variable in the model. $x_{i j}=0$ when $\operatorname{arc}\left(v_{i}, v_{j}\right)$ is not included in the fixed route and $x_{i j}=1$ when $\operatorname{arc}\left(v_{i}, v_{j}\right)$ is included in the fixed route. 


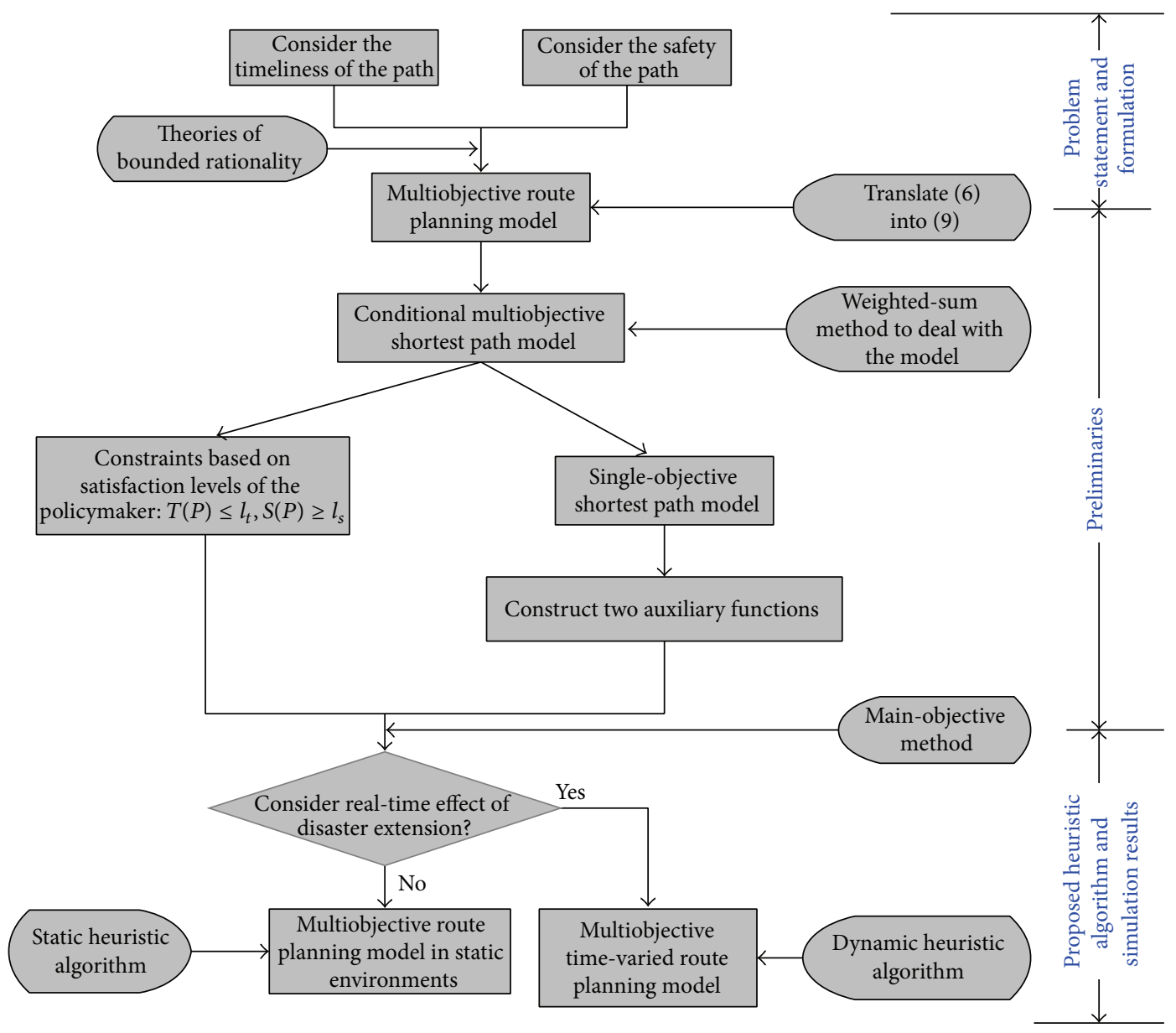

FIGURE 1: Method for studying multiobjective route planning problem in emergency logistics management.

(6) Suppose that $P$ denotes a feasible route from the source node to the destination node, which is constituted based on the constraints as follows:

$$
\begin{gathered}
\sum_{j=1, j \neq i}^{n} x_{i j}-\sum_{j=1, j \neq i}^{n} x_{j i}= \begin{cases}1, & i=1, \\
-1, & i=n, \\
0, & \text { otherwise, }\end{cases} \\
\sum_{j=1, j \neq i}^{n} x_{i j}= \begin{cases}\leq 1, & i \neq n, \\
0, & i=n,\end{cases} \\
x_{i j}=0,1, \quad i, j \in\{1,2, \ldots, n\} .
\end{gathered}
$$

Constraint (2) restricts the value of $x_{i j}$ to constitute route $P$ and Constraint (3) ensures that there are no circles in the route $P$. Constraint (4) is the $0-1$ integer constraint of the decision variable $x_{i j}$.

2.2. Bounded Rationality in Decision-Making. After the 1950s, it was recognized that the entire rationality model based on the hypothesis of "economic man" is actually an ideal model, so it is impossible to guide decision-making in practice. To solve this problem, Herbert Simon proposed the bounded rationality model, where the "social man" was used instead of "economic man" [19]. Simon's bounded rationality model is a relatively realistic model, and it considered that human rationality is a bounded rationality between entire rationality and entire irrationality. The main points of this theory are issued as follows.

(1) There are some contradictions in the connotations of means-ends chain, so single analysis of means-ends chain would lead to inaccurate results.

(2) Decision-makers seek something that is bounded rational rather than entirely rational.

(3) Decision-makers seek something that is "good enough," that is, something that is satisfactory, rather than something that is best.

Above all, decision-makers tend to seek a route that is "good enough" but not the best for the practical problems.

\subsection{Multiobjective Route Planning Model for Emergency Logis-} tics Management. First of all, time is one of the most precious resources under disaster conditions. We are able to grab the initiative to save lives and fight for victory if we gain the resource of time. Therefore time is a decision-making objective that cannot be ignored under any emergency situation. 
Furthermore, observing the extension processes of some disasters such as flood, hurricane, and gas leak, we can find that the vulnerability of humans on each arc of the network will differ with the extension of disasters. The probit approach is usually used to determine the vulnerability of humans during disaster time, based on which lethality of humans under disaster conditions can be estimated [20]. Let $q_{i j}$ denote the lethality of humans from node $v_{i}$ to $v_{j}$; then the safety of $\operatorname{arc}\left(v_{i}, v_{j}\right)$ can be acquired as follows: $s_{i j}=1-q_{i j}$, where $0 \leq q_{i j} \leq 1$.

Hence, a multiobjective route planning model can be built taking into account both time factor and route safety factor. The objectives of the model are to minimize total travel time along the route and to maximize the safety through the route, respectively, where the route safety is modeled as the product of safety through arcs included in the path. The model can be formulated as follows.

Model I:

$$
\begin{aligned}
& \min T(P)=\sum_{\left(v_{i}, v_{j}\right) \in P} t_{i j}, \\
& \max S(P)=\prod_{\left(v_{i}, v_{j}\right) \in P} s_{i j},
\end{aligned}
$$

s.t.

$$
\begin{aligned}
& T(P) \leq l_{t}, \\
& S(P) \geq l_{s} .
\end{aligned}
$$

Here, $l_{t}, l_{s}$ denote the satisfaction level of travel time and route safety through the selected route given by the emergency makers, respectively; Constraints (7) and (8) are conditions based on the theories of bounded rationality.

\section{Preliminaries}

3.1. Classical Algorithms to Solve Single-Objective Shortest Path Problem. Classical algorithms to solve single-objective shortest path problem include static algorithms and dynamic algorithms. Dijkstra algorithm is one of the classical algorithms to solve shortest path problem in static environments effectively [21]. The basic idea of the algorithm is to find shortest route from the source node step by step. Dijkstra algorithm maintains labels $P$ and $T$ with each node $v_{i}$, which are the total weight of the shortest path and an upper bound of the total weight on the shortest path from the source node to each node $v_{i}$, respectively. At any intermediate step, the algorithm modifies the $T$ labels of nodes and sets $P$ label for a certain node; then it adds the node to the set of nodes with $P$ labels. Thus the number of nodes with $P$ labels will increase by one after each step and the shortest paths from the source node to all the other nodes in the network will be found after at most $(n-1)$ steps.

$A^{*}$ algorithm [22] is another classical algorithm to solve shortest path problem in static environments effectively. $A^{*}$ algorithm uses heuristic information to narrow the search space in the search, so we can get the optimal solution faster and more effectively than Dijkstra algorithm.
Dijkstra algorithm and $A^{*}$ algorithm are efficient in static networks, but they are not suitable for solving shortest path problems in dynamic networks, such as dynamic environments with weight on each road section changing constantly. $D^{*}$ algorithm $[23,24]$, that is, dynamic $A^{*}$ algorithm, is one of the classical algorithms to solve shortest path problem in dynamic environments effectively, which is mainly used in route planning for robots. The basic idea of the algorithm is to check the changes of the next node or the adjacent node on the shortest route to update the shortest route when moving to the target point.

3.2. Construction of Auxiliary Functions. First we construct a new network $G_{1}=\left(V, E_{1}\right)$, where $E_{1}=\left\{e: e=\left(v_{i}, v_{j}\right)\right.$ and $\left.s_{i j}>0\right\}$. It is necessary to translate it into a minimization problem by using $\max S(P)=-\min S(P)$ since (6) is a maximization problem. In addition, (6) is in the form of product with respect to the weight of $\operatorname{arc}\left(v_{i}, v_{j}\right)$. In order to use the shortest path algorithm to solve (6), it is necessary to translate (6) into a form of summation with respect to the weight of arc $\left(v_{i}, v_{j}\right)$ by using $S(P)=\exp [\ln S(P)]$. By this way, we can obtain an equivalent form of (6) in network $G_{1}$ as follows:

$$
\min \sum_{\left(v_{i}, v_{j}\right) \in P}\left|\ln s_{i j}\right| .
$$

By this way, the multiobjective route planning model proposed in Section 2.3 can be translated into a conditional multiobjective shortest path model based on the theories of bounded rationality as follows.

Model II: (5) and (9) s.t. (7) and (8).

Suppose that $T_{\min }, S_{\min }$ denote the optimal value of (5) and (6), respectively. And $T_{\max }, S_{\max }$ denote the value of (5) and (6) corresponding to the longest route between the source node and destination node, respectively. Then we use the weighted-sum method to deal with (5) and (9) and convert them into a single-objective model as follows.

Model III:

$$
\begin{array}{r}
\min F(\theta)=\theta \frac{|\ln S(P)|-\left|\ln S_{\max }\right|}{\left|\ln S_{\min }\right|-\left|\ln S_{\max }\right|}+\eta \frac{T(P)-T_{\min }}{T_{\max }-T_{\min }} \\
S_{\min }>0
\end{array}
$$

Here, $(\theta, \eta) \in \mathbf{R}=\{(\theta, \eta) \mid \theta, \eta \geq 0, \theta+\eta=1\}$ is the vector of weighting coefficients. According to the theorem about weighted-sum method [25-27], the minimizer of this combined function is Pareto optimal and the solution is a noninferior solution of multiobjective optimization problem with respect to (5) and (9). Suppose that $P_{\theta}$ is the best path obtained by Model III corresponding to an already known weighting coefficient $\theta$. Based on Model III, we can obtain two auxiliary functions as follows:

$$
\begin{aligned}
& f_{t}(\theta)=T\left(P_{\theta}\right)=\sum_{\left(v_{i}, v_{j}\right) \in P_{\theta}} t_{i j}, \\
& f_{s}(\theta)=S\left(P_{\theta}\right)=\prod_{\left(v_{i}, v_{j}\right) \in P_{\theta}} s_{i j} .
\end{aligned}
$$


In order to propose a feasible algorithm to solve Model III, first we construct a new factor $w_{i j}=\theta \cdot\left|\ln s_{i j}\right| / \mid \ln S_{\max }-$ $\ln S_{\min } \mid+\eta \cdot t_{i j} /\left(T_{\max }-T_{\min }\right)$ for $\operatorname{arc}\left(v_{i}, v_{j}\right)$, where $0<s_{i j} \leq 1$; then we have Lemmas 1 and 2 as follows.

Lemma 1. Model III can be solved through single-objective shortest path algorithms, and the optimum solution $P_{\theta}$, namely, is the shortest route with respect to the new factor $w_{i j}$.

Proof. Consider the following:

$$
\begin{aligned}
F(\theta)= & \theta \frac{|\ln S(P)|-\left|\ln S_{\max }\right|}{\left|\ln S_{\min }\right|-\left|\ln S_{\max }\right|}+\eta \frac{T(P)-T_{\min }}{T_{\max }-T_{\min }} \\
= & \theta \cdot \frac{|\ln S(P)|}{\left|\ln S_{\max }-\ln S_{\min }\right|}+\eta \cdot \frac{T(P)}{\left(T_{\max }-T_{\min }\right)} \\
& -b_{1}-b_{2}
\end{aligned}
$$

where $b_{1}=\theta \cdot\left|\ln S_{\min } /\left(\ln S_{\max }-\ln S_{\min }\right)\right|, b_{2}=\eta \cdot T_{\min } /\left(T_{\max }-\right.$ $\left.T_{\min }\right)$, and $b_{1}, b_{2}$ are constants for a known network graph $G_{1}$. Then $F(\theta)=\sum_{\left(v_{i}, v_{j}\right) \in P}\left(\left(\theta /\left(\left|\ln S_{\min }\right|-\left|\ln S_{\max }\right|\right)\right)\left|\ln s_{i j}\right|+\right.$ $\left.\left.\left(\eta / T_{\max }-T_{\min }\right)\right) t_{i j}\right)-b_{1}-b_{2}$. Then $\min F(\theta)=\min \sum_{\left(v_{i}, v_{j}\right) \in P}$ $w_{i j}-b_{1}-b_{2}$. Therefore, the shortest route with respect to the new factor $w_{i j}$ can be obtained by applying an existing singleobjective shortest path algorithm, such as $A^{*}$ algorithm or $D^{*}$ algorithm, and the obtained route, namely, is the optimum solution of Model III with respect to the vector of weighting coefficients $(\theta, \eta)$.

Lemma 2. Equations (11) and (12) are increasing functions of $\theta$, respectively, and (11) can obtain the minimum value of $T(P)$ when $\theta=0$ while (12) can obtain the maximum value of $S(P)$ when $\theta=1$.

Proof. Let $P_{\theta 1}, P_{\theta 2}$ be the optimum solution of Model III with respect to $\theta_{1}$ and $\theta_{2}$, respectively, where $0 \leq \theta_{1}<\theta_{2} \leq 1$. Based on Model III and Lemma 1, we can obtain that

$$
\begin{gathered}
\sum_{\left(v_{i}, v_{j}\right) \in P_{\theta 1}}\left(\frac{\theta_{1}}{\left|\ln S_{\min }\right|-\left|\ln S_{\max }\right|}\left|\ln s_{i j}\right|+\frac{1-\theta_{1}}{T_{\max }-T_{\min }} t_{i j}\right) \\
\leq \sum_{\left(v_{i}, v_{j}\right) \in P_{\theta 2}}\left(\frac{\theta_{1}}{\left|\ln S_{\min }\right|-\left|\ln S_{\max }\right|}\left|\ln s_{i j}\right|\right. \\
\left.\quad+\frac{1-\theta_{1}}{T_{\max }-T_{\min }} t_{i j}\right), \\
\sum_{\left(v_{i}, v_{j}\right) \in P_{\theta 1}}\left(\frac{\theta_{2}}{\left|\ln S_{\min }\right|-\left|\ln S_{\max }\right|}\left|\ln s_{i j}\right|+\frac{1-\theta_{2}}{T_{\max }-T_{\min }} t_{i j}\right) \\
\sum_{\left(v_{i}, v_{j}\right) \in P_{\theta 2}}\left(\frac{\theta_{2}}{\left|\ln S_{\min }\right|-\left|\ln S_{\max }\right|}\left|\ln s_{i j}\right|\right. \\
\left.\quad+\frac{1-\theta_{2}}{T_{\max }-T_{\min }} t_{i j}\right) .
\end{gathered}
$$

Therefore, $\quad \theta_{1}\left(\sum_{\left(v_{i}, v_{j}\right) \in P_{\theta 1}}\left|\ln s_{i j}\right|-\sum_{\left(v_{i}, v_{j}\right) \in P_{\theta 2}}\left|\ln s_{i j}\right|\right) /$ $\left(\left|\ln S_{\min }\right|-\left|\ln S_{\max }\right|\right)+\left(1-\theta_{1}\right)\left(\sum_{\left(v_{i}, v_{j}\right) \in P_{\theta 1}} t_{i j}-\sum_{\left(v_{i}, v_{j}\right) \in P_{\theta 2}} t_{i j}\right) /$ $\left(T_{\max }-T_{\text {min }}\right) \leq 0, \theta_{2}\left(\sum_{\left(v_{i}, v_{j}\right) \in P_{\theta 1}}\left|\ln s_{i j}\right|-\sum_{\left(v_{i}, v_{j}\right) \in P_{\theta 2}}\left|\ln s_{i j}\right|\right) /$ $\left(\left|\ln S_{\min }\right|-\left|\ln S_{\max }\right|\right)+\left(1-\theta_{2}\right)\left(\sum_{\left(v_{i}, v_{j}\right) \in P_{\theta 1}} t_{i j}-\sum_{\left(v_{i}, v_{j}\right) \in P_{\theta 2}} t_{i j}\right) /$ $\left(T_{\max }-T_{\min }\right) \geq 0$. Then we can get $\sum_{\left(v_{i}, v_{j}\right) \in P_{\theta 1}}\left|\ln s_{i j}\right|-$ $\sum_{\left(v_{i}, v_{j}\right) \in P_{\theta 2}}\left|\ln s_{i j}\right| \geq 0, \sum_{\left(v_{i}, v_{j}\right) \in P_{\theta 1}} t_{i j}-\sum_{\left(v_{i}, v_{j}\right) \in P_{\theta 2}} t_{i j} \leq 0$; that is, $f_{s}\left(\theta_{1}\right) \leq f_{s}\left(\theta_{2}\right)$ and $f_{t}\left(\theta_{1}\right) \leq f_{t}\left(\theta_{2}\right)$. So we can conclude that (11) and (12) are increasing functions of $\theta$, respectively. Let $P_{0}, P_{1}$ denote the optimum solution of Model III with respect to the vector of weighting coefficients $(0,1)$ and $(1,0)$, respectively. According to Model III and Lemma 1, we can obtain that $\min F(0)=\min \sum_{\left(v_{i}, v_{j}\right) \in P} t_{i j} /\left(T_{\max }-T_{\min }\right)$ and $\min F(0)=\sum_{\left(v_{i}, v_{j}\right) \in P_{0}}\left(1 /\left(T_{\max }-T_{\min }\right)\right) t_{i j}=\sum_{\left(v_{i}, v_{j}\right) \in P_{0}} t_{i j} /$ $\left(T_{\max }-T_{\min }\right)=f_{t}(0) /\left(T_{\max }-T_{\min }\right)$, so we can conclude that $f_{t}(0)=\min \sum_{\left(v_{i}, v_{j}\right) \in P} t_{i j}=\min T(P)$. Similarly, we can get $f_{s}(1)=\min \sum_{\left(v_{i}, v_{j}\right) \in P}\left|\ln s_{i j}\right|=\max \prod_{\left(v_{i}, v_{j}\right) \in P} s_{i j}=\max S(P)$. The conclusion is obtained.

\subsection{Main-Objective Method to Deal with Multiobjective Opti-} mization Problems. If a feasible route from the source node $v_{1}$ to the destination node $v_{n}$ is the best path obtained by Model III and satisfies Constraints (7) and (8), we can easily obtain that the route is a noninferior solution of Model II, that is, a noninferior solution of Model I. According to Lemmas 1 and 2 and Constraints (7) and (8), the set of noninferior solutions can be generated by using single-objective shortest path algorithms to solve Model III when $\tau$ varies within the interval $[0,1]$.

According to Lemma 2, the optimization objectives of route timeliness and safety conflict each other in the process of multiobjective route planning within the set of noninferior solutions. To solve this problem, we use the main-objective method to deal with the multiobjective route planning model. The main-objective method is a method of solving multiobjective optimization problems. The basic idea of this method is to seize the main objective and take into account other requirements, that is, to select a target from the multiobjectives as the main target; other objectives only need to meet certain requirements. The selection of main objective in multiobjective optimization problems depends on the needs of decision-makers. Therefore, the optimization objectives of the multiobjective route planning model in actual emergency logistics management can be divided into major and secondary optimal objectives. In order to facilitate the description, we assume the optimization objective based on (6) as the main target of the multiobjective route planning model. Accordingly, the optimal solution of the multiobjective route planning model can be defined as follows.

Definition 3. $R^{*}$ is the optimal solution of the multiobjective route planning model if $T\left(R^{*}\right)=\min \{T(R): R \in Q\}$, where $Q$ is the set of all the noninferior solutions to Model I.

According to Lemma 2 and Definition 3, we have a deduction of Lemma 2 as follows. 
Deduction 1. Let $\theta, \zeta \in\left[\theta_{1}, \theta_{2}\right] \subseteq[0,1]$ and $P_{\zeta}$ denote the shortest path obtained by Model III with respect to the weighting coefficient $\zeta$; then we can obtain that

(1) for $\forall \zeta \in\left[\theta_{1}, \theta\right] T\left(P_{\zeta}\right)<l_{t}$ and $S\left(P_{\zeta}\right) \leq S\left(P_{\theta}\right)$ if $f_{t}(\theta)<$ $l_{t}$

(2) for $\forall \zeta \in\left[\theta, \theta_{2}\right] T\left(P_{\zeta}\right)>l_{t}$ and $S\left(P_{\zeta}\right) \geq S\left(P_{\theta}\right)$ if $f_{t}(\theta)>$ $l_{t}$

(3) $P^{*}=P_{\theta}$ if $f_{t}(\theta)=l_{t}$ and $S\left(P_{\theta}\right) \geq l_{s}$.

The optimal solution of the multiobjective route planning model can be acquired based on Definition 3 if $Q$ is obtained. But the algorithm based on this idea is of high complexity, which cannot meet the demand of emergency decisionmaking. Therefore, according to the auxiliary functions constructed in Section 3.2 and their properties, we propose a heuristic method to generate the set of noninferior solutions and find the optimal solution in the generated set. The proposed algorithm is a fast, approximate algorithm.

\section{The Proposed Heuristic Algorithm}

In general, the approach of solving a multiobjective shortest path problem is to convert the multiobjective shortest path problem into a single-objective shortest path problem based on the weighted-sum method $[15,25,28]$. However, the difficulty of using weighted-sum method is how to find the reasonable weight coefficients to reflect the importance of each single objective in the multiobjective optimization problem. To solve this problem, we proposed a heuristic method. In our method, different single-objective shortest path algorithms are used to generate the set of noninferior solutions by solving Model III when $\tau$ varies within the interval $[0,1]$, and the satisfaction levels of secondary optimization objectives were converted into constraints, and the optimal route will be obtained finally by searching best solution of Model III in the direction of satisfaction of the main optimization objective in the multiobjective route planning model increasing. In order to improve the efficiency of the algorithm, it is not finding the optimal solution at an even pace but quickly searching the optimal solution by reducing the current interval $\left[\theta_{2}, \theta_{1}\right]$ according to Deduction 1.

4.1. Static Heuristic Algorithm to Solve Model I Based on $A^{*}$ Algorithm. In our approach, first we remove the arcs that do not meet the safety conditions in the network, and then the Dijkstra algorithm is applied to find the shortest route to obtain $T_{\min }$ and $S_{\min }$. What is more, it is used to obtain $T_{\max }$ and $S_{\max }$ based on Lemma 2, respectively, so as to construct the new factor $w_{i j}$ for arc $\left(v_{i}, v_{j}\right)$. On the other hand, the $A^{*}$ algorithm is used to find the optimum solution $P_{\theta}$ of Model III corresponding to the weight vector $(\theta, \eta)$ in the network based on Lemma 1. Finally, according to satisfactory levels given by the decision-maker, the optimal route of the multiobjective route planning model in static environments can be found.

Pseudocode 1 presents the pseudocode of the heuristic algorithm to solve the multiobjective route planning model in static environments, considering the sets, parameters, and variables as defined in Section 2.1.

4.2. Dynamic Heuristic Algorithm to Solve Model I Based on $D^{*}$ Algorithm. In many cases, the travel conditions on the arcs may be greatly affected by disaster extension especially under some disasters, like hurricane, flood, rainstorm, and gas leak, which will extend gradually in time and space. The route safety and congestion of each arc will change dynamically under disaster extension, and the changing extent will differ with the positions of the arcs and the severity of the disaster. In static environments, $P_{0}$ and $P_{1}$ can be obtained through the classical Dijkstra algorithm and Model III can be obtained through the $A^{*}$ algorithm, and, after several cycles to solve Model III, Model II can be finally solved when obtaining the appropriate vector of weighting coefficients $\left(\theta^{*}, \eta^{*}\right)$. But in dynamic environments, the three singleobjective models based on (5), (6), and (8) cannot be solved through either of the above two algorithms. To solve this problem, as presented in Pseudocode 2, the classical Dijkstra algorithm is replaced by the modified Dijkstra algorithm [15], and the $A^{*}$ algorithm is replaced by the $D^{*}$ algorithm; other steps of the algorithm to solve the route planning model in dynamic environments are the same as those of the algorithm in Section 4.1. Pseudocode 2 presents the pseudocode of the heuristic algorithm to solve the multiobjective route planning model in dynamic environments.

4.3. Algorithm Advantage. The proposed algorithm not only is conducive to solving problems for the emergency decisionmakers, but also can help the decision-makers to raise problems. When the satisfaction levels of decision-makers are known, the proposed algorithm can be used to find the optimal solution of multiobjective route planning model for emergency logistics management, that is, problem solution. In addition, the variations of $S(P)$ and $T(P)$ with the value of $\theta$ can be acquired by using the proposed algorithm when the satisfaction levels of decision-makers are unknown, and, according to the above two curves, the decision-maker can set different satisfaction levels for the optimization objective functions in the multiobjective route planning model to put forward different optimization problems, that is, problem presentation.

Thus, the proposed algorithm in Section 4 can be used as an auxiliary tool for emergency decisions, which can be used to find the optimal route of multiobjective route planning model and get reasonable weighting coefficients.

\section{Computational Experiments}

In order to show the effectiveness and feasibility of the model and algorithm, in this communication, numerical experiments are carried out to verify Lemma 2 in Section 5.1 and test the algorithm advantages in Sections 5.2 to 5.3.

5.1. Results of Model III When $\tau$ Varies within the Interval $[0,1]$. We carry out our computational experiments on a logistics network with 36 nodes and the structure of 
(1) Initialization (cycles counter $\mathrm{NC}=0$ ). Let $G=(V, E), \theta_{1}=0, \theta_{2}=1$, set the value of fundamental parameters of the heuristic algorithm including the maximum number of cycles $\mathrm{NC}_{\max }$, the satisfaction level of travel time and safety probability through the selected route $l_{t}, l_{s}$, growth rate of weighting coefficient $\lambda$ where $l_{t}>0, l_{s}>0, \lambda \in(0,1)$.

(2) Construct a new network $G_{1}=(V, E)$, where $E_{1}=\left\{e: e=\left(v_{i}, v_{j}\right)\right.$ and $\left.s_{i j} \geq l_{s}\right\}$.

(3) $\theta=0, \eta=1-\theta$, let $w_{i j}$ be the weight on $\operatorname{arc}\left(v_{i}, v_{j}\right), w_{i j}=t_{i j}$, use Dijkstra algorithm to obtain the shortest route $P_{\theta}$ with respect to $w_{i j}$ and obtain the corresponding optimal value $T_{\min }$. According to Lemma 2, $S_{\min }=S\left(P_{\theta}\right)$.

(3.1) If $T_{\min }>l_{t}, P^{*}$ has no solution, the algorithm terminates.

(3.2) Else if $T_{\min }=l_{t}, P^{*}=P_{\theta}, \theta^{*}=\theta, \eta^{*}=1-\theta^{*}$, go to step 5 .

(4) $\theta=1, \eta=1-\theta$, let $w_{i j}$ be the weight on $\operatorname{arc}\left(v_{i}, v_{j}\right), w_{i j}=\left|\ln s_{i j}\right|$, use Dijkstra algorithm to obtain the shortest route $P_{\theta}$ with respect to $w_{i j}$ and obtain the corresponding optimal value $S_{\max }$. According to Lemma 2, $T_{\max }=T\left(P_{\theta}\right)$.

(4.1) Else if $T_{\max } \leq l_{t}, P^{*}=P_{\theta}, \theta^{*}=\theta, \eta^{*}=1-\theta^{*}$, go to step 5 .

(4.2) Else $\theta=0, \eta=1-\theta, P^{*}=P_{\theta}, \theta^{*}=0, \eta^{*}=1-\theta^{*}$.

(4.2.1) If $\mathrm{NC} \leq \mathrm{NC}_{\max }, \theta \leftarrow \theta_{1}+\lambda \cdot\left(\theta_{2}-\theta_{1}\right), w_{i j}=\theta \cdot\left|\ln s_{i j}\right| /\left|\ln S_{\max }-\ln S_{\min }\right|+\eta \cdot t_{i j} /\left(T_{\max }-T_{\min }\right)$, use the $A^{*}$ algorithm to obtain the shortest route $P_{\theta}$ with respect to $w_{i j}$.

(4.2.1.1) If $f_{t}(\theta)>l_{t}, \theta_{2}=\theta, \mathrm{NC}=\mathrm{NC}+1$, go to step 4.2.1.

(4.2.1.2) Else if $f_{t}(\theta)=l_{t}, P^{*}=P_{\theta}, \theta^{*}=\theta, \eta^{*}=1-\theta^{*}$, go to step 5 .

(4.2.1.3) Else, $\theta_{1}=\theta, \mathrm{NC}=\mathrm{NC}+1, P^{*}=P_{\theta}, \theta^{*}=\theta, \eta^{*}=1-\theta^{*}$, go to step 4.2.1.

(5) If $S\left(P^{*}\right) \geq l_{s}, P^{*}$ is the optimal solution selected and $\left(\theta^{*}, \eta^{*}\right)$ is the corresponding vector of weighting coefficients, the algorithm terminates.

(6) Else, $P^{*}$ has no solution, the algorithm terminates.

Pseudocode 1: Pseudocode for the static heuristic algorithm.

(1) Initialization (cycles counter $\mathrm{NC}=0$ ). Let $G=(V, E), \theta_{1}=0, \theta_{2}=1$, set the value of fundamental parameters of the heuristic algorithm including the maximum number of cycles $\mathrm{NC}_{\max }$, the satisfaction level of travel time and safety probability through the selected route $l_{t}, l_{s}$, growth rate of weighting coefficient $\lambda$ where $l_{t}>0, l_{s}>0, \lambda \in(0,1)$.

(2) Construct a new network $G_{1}=(V, E)$, where $E_{1}=\left\{e: e=\left(v_{i}, v_{j}\right)\right.$ and $\left.s_{i j} \geq l_{s}\right\}$.

(3) $\theta=0, \eta=1-\theta$, let $w_{i j}$ be the weight on arc $\left(v_{i}, v_{j}\right), w_{i j}=t_{i j}$, use the modified Dijkstra algorithm to obtain the shortest route $P_{\theta}$ with respect to $w_{i j}$ and obtain the corresponding optimal value $T_{\min }$. According to Lemma 2, $S_{\min }=S\left(P_{\theta}\right)$.

(3.1) If $T_{\min }>l_{t}, P^{*}$ has no solution, the algorithm terminates.

(3.2) Else if $T_{\min }=l_{t}, P^{*}=P_{\theta}, \theta^{*}=\theta, \eta^{*}=1-\theta^{*}$, go to step 5 .

(4) $\theta=1, \eta=1-\theta$, let $w_{i j}$ be the weight on $\operatorname{arc}\left(v_{i}, v_{j}\right), w_{i j}=\left|\ln s_{i j}\right|$, use the modified Dijkstra algorithm to obtain the shortest route $P_{\theta}$ with respect to $w_{i j}$ and obtain the corresponding optimal value $S_{\max }$. According to Lemma 2, $T_{\max }=T\left(P_{\theta}\right)$.

(4.1) Else if $T_{\max } \leq l_{t}, P^{*}=P_{\theta}, \theta^{*}=\theta, \eta^{*}=1-\theta^{*}$, go to step 5 .

(4.2) Else $\theta=0, \eta=1-\theta, P^{*}=P_{\theta}, \theta^{*}=0, \eta^{*}=1-\theta^{*}$.

(4.2.1) If $\mathrm{NC} \leq \mathrm{NC}_{\max }, \theta \leftarrow \theta_{1}+\lambda \cdot\left(\theta_{2}-\theta_{1}\right), w_{i j}=\theta \cdot\left|\ln s_{i j}\right| /\left|\ln S_{\max }-\ln S_{\min }\right|+\eta \cdot t_{i j} /\left(T_{\max }-T_{\min }\right)$, use

the $D^{*}$ algorithm to obtain the shortest route $P_{\theta}$ with respect to $w_{i j}$.

(4.2.1.1) If $f_{t}(\theta)>l_{t}, \theta_{2}=\theta, \mathrm{NC}=\mathrm{NC}+1$, go to step 4.2.1.

(4.2.1.2) Else if $f_{t}(\theta)=l_{t}, P^{*}=P_{\theta}, \theta^{*}=\theta, \eta^{*}=1-\theta^{*}$, go to step 5 .

(4.2.1.3) Else, $\theta_{1}=\theta, \mathrm{NC}=\mathrm{NC}+1, P^{*}=P_{\theta}, \theta^{*}=\theta, \eta^{*}=1-\theta^{*}$, go to step 4.2.1.

(5) If $S\left(P^{*}\right) \geq l_{s}, P^{*}$ is the optimal solution selected and $\left(\theta^{*}, \eta^{*}\right)$ is the corresponding vector of weighting coefficients, the algorithm terminates.

(6) Else, $P^{*}$ has no solution, the algorithm terminates.

Pseudocode 2: Pseudocode for the dynamic heuristic algorithm.

an emergency logistics network is shown in Figure 2. Suppose the disaster happens at node $(0,0)$, that is, the source node, and node $(5,5)$ denotes the position of exit, that is, the destination node. Suppose that the period of logistics operation is short, namely, in a static environment. The parameters of the emergency logistics network, such as the length of each arc $l_{i j}$, route safety of $\operatorname{arc}\left(v_{i}, v_{j}\right) s_{i j}$, the initial travel speed $u_{i j}^{0}$, and the congestion coefficient $\xi_{i j}$, are shown in Table 1.

In order to verify Lemma 2 in Section 3.2, first we construct a new network $G_{1}=(V, E)$, where $E_{1}=\{e: e=$ $\left(v_{i}, v_{j}\right)$ and $\left.s_{i j}>0\right\}$. Let $\theta$ vary within the interval $[0,1]$, let the interval of each two adjacent values be 0.02 , and let the constructed parameter $w_{i j}=\theta \cdot\left|\ln s_{i j}\right| /\left|\ln S_{\max }-\ln S_{\min }\right|+$ $\eta \cdot t_{i j} /\left(T_{\max }-T_{\min }\right)$ be assigned to weight on arc $\left(v_{i}, v_{j}\right)$, and then, based on Lemma 1, we can obtain the shortest path $P_{\theta}$ from node $(0,0)$ to node $(5,5)$ of Model III with respect to weighting coefficient $\theta$ by using the $A^{*}$ algorithm. From the parameters shown in Table 1, we can obtain the travel time and route safety of these paths. Figures 3 and 4 show the variation of $f_{t}$ and $f_{s}$ with the value of $\theta$. From Figures 3 and 4 we can see that $f_{t}$ and $f_{s}$ are increasing functions with respect to $\theta$, respectively. The computational 
TABLE 1: Parameters of the emergency logistics network.

\begin{tabular}{|c|c|c|c|c|c|}
\hline$\left(v_{i}, v_{j}\right)$ & $\begin{array}{l}\left(l_{i j}, u_{0 i j}, \xi_{i j},\left|\ln q_{i j}\right|\right) \\
(\mathrm{m}, \mathrm{m} / \mathrm{min},-,-)\end{array}$ & $\left(v_{i}, v_{j}\right)$ & $\begin{array}{l}\left(l_{i j}, u_{0 i j}, \xi_{i j},\left|\ln q_{i j}\right|\right) \\
(\mathrm{m}, \mathrm{m} / \mathrm{min},-,-)\end{array}$ & $\left(v_{i}, v_{j}\right)$ & $\begin{array}{l}\left(l_{i j}, u_{0 i j}, \xi_{i j},\left|\ln q_{i j}\right|\right) \\
(\mathrm{m}, \mathrm{m} / \mathrm{min},-,-)\end{array}$ \\
\hline$((0,0),(0,1))$ & $\begin{array}{c}(93,107,0.7058 \\
0.0397)\end{array}$ & $((1,0),(2,0))$ & $\begin{array}{c}(116,95,0.7105 \\
0.0435)\end{array}$ & $((1,0),(1,1))$ & $\begin{array}{c}(86,117,0.7731 \\
0.0377)\end{array}$ \\
\hline$((0,0),(1,0))$ & $\begin{array}{c}(57,119,0.7866 \\
0.0453)\end{array}$ & $((0,1),(1,1))$ & $\begin{array}{c}(110,117,0.7742, \\
0.0511)\end{array}$ & $((1,1),(1,2))$ & $\begin{array}{c}(90,100,0.7458 \\
0.0379)\end{array}$ \\
\hline$((0,1),(0,2))$ & $\begin{array}{c}(43,113,0.7779 \\
0.0354)\end{array}$ & $((1,1),(2,1))$ & $\begin{array}{c}(107,115,0.7663 \\
0.0458)\end{array}$ & & \\
\hline$((1,2),(1,3))$ & $\begin{array}{c}(120,116,0.8372 \\
0.0114)\end{array}$ & $((2,0),(3,0))$ & $(42,83,0.8797,0.0251)$ & $((3,0),(3,1))$ & $\begin{array}{c}(100,101,0.8429 \\
0.0186)\end{array}$ \\
\hline$((0,3),(1,3))$ & $(95,93,0.8387,0.0211)$ & $((2,1),(3,1))$ & $\begin{array}{c}(37,120,0.8941, \\
0.0114)\end{array}$ & $((3,0),(4,0))$ & $\begin{array}{c}(32,103,0.8985 \\
0.0133)\end{array}$ \\
\hline$((2,0),(2,1))$ & $(32,79,0.8105,0.0147)$ & $((0,2),(1,2))$ & $\begin{array}{c}(31,115,0.8078 \\
0.0175)\end{array}$ & $((2,1),(2,2))$ & $\begin{array}{c}(87,115,0.8665 \\
0.0181)\end{array}$ \\
\hline$((0,2),(0,3))$ & $\begin{array}{c}(107,93,0.8351 \\
0.0212)\end{array}$ & $((1,2),(2,2))$ & $\begin{array}{c}(68,84,0.8996 \\
0.0140)\end{array}$ & & \\
\hline$((2,2),(2,3))$ & $\begin{array}{c}(44,85,0.8776 \\
0.0145)\end{array}$ & $((2,2),(3,2))$ & $(57,85,0.8290,0.0171)$ & & \\
\hline$((0,3),(0,4))$ & $\begin{array}{c}(63,87,0.9503 \\
0.0099)\end{array}$ & $((5,1),(5,2))$ & $\begin{array}{c}(117,108,0.9245, \\
0.0004)\end{array}$ & $((4,2),(5,2))$ & $\begin{array}{c}(117,97,0.9963 \\
0.0020)\end{array}$ \\
\hline$((0,4),(0,5))$ & $\begin{array}{c}(77,84,0.9363 \\
0.0085)\end{array}$ & $((4,0),(4,1))$ & $\begin{array}{c}(68,100,0.9168 \\
0.0019)\end{array}$ & $((1,3),(2,3))$ & $\begin{array}{c}(58,82,0.9922 \\
0.0045)\end{array}$ \\
\hline$((1,4),(1,5))$ & $\begin{array}{c}(64,99,0.9367 \\
0.0033)\end{array}$ & $((4,1),(4,2))$ & $\begin{array}{c}(99,117,0.9364 \\
0.0062)\end{array}$ & $((2,3),(3,3))$ & $\begin{array}{c}(120,92,0.9176 \\
0.0051)\end{array}$ \\
\hline$((1,3),(1,4))$ & $\begin{array}{c}(65,81,0.9941 \\
0.0025)\end{array}$ & $((4,2),(4,3))$ & $\begin{array}{c}(51,106,0.9268, \\
0.0079)\end{array}$ & $((3,3),(4,3))$ & $\begin{array}{c}(84,93,0.9842 \\
0.0039)\end{array}$ \\
\hline$((2,3),(2,4))$ & $\begin{array}{c}(105,90,0.9199 \\
0.0027)\end{array}$ & $((4,0),(5,0))$ & $\begin{array}{c}(111,118,0.9425, \\
0.0030)\end{array}$ & $((0,4),(1,4))$ & $\begin{array}{c}(38,98,0.9397 \\
0.0037)\end{array}$ \\
\hline$((2,4),(2,5))$ & $(30,85,0.9167,0.0075)$ & $((3,1),(4,1))$ & $\begin{array}{c}(52,112,0.9246 \\
0.0080)\end{array}$ & $((1,4),(2,4))$ & $\begin{array}{c}(91,108,0.9657 \\
0.0006)\end{array}$ \\
\hline$((3,1),(3,2))$ & $\begin{array}{c}(70,120,0.9697 \\
0.0036)\end{array}$ & $((4,1),(5,1))$ & $\begin{array}{c}(42,76,0.9967 \\
0.0094)\end{array}$ & $((2,4),(3,4))$ & $(78,85,0.9247,0.0001)$ \\
\hline$((3,2),(3,3))$ & $\begin{array}{c}(82,91,0.9295 \\
0.0034)\end{array}$ & $((3,2),(4,2))$ & $\begin{array}{c}(59,110,0.9329, \\
0.0014)\end{array}$ & $((0,5),(1,5))$ & $\begin{array}{c}(85,102,0.9320 \\
0.0025)\end{array}$ \\
\hline$((3,3),(3,4))$ & $\begin{array}{c}(116,91,0.9786 \\
0.0040)\end{array}$ & $((5,2),(5,3))$ & $\begin{array}{c}(33,110,0.9247 \\
0.0041)\end{array}$ & $((1,5),(2,5))$ & $\begin{array}{c}(80,102,0.9868, \\
0.0034)\end{array}$ \\
\hline$((3,4),(3,5))$ & $\begin{array}{c}(48,92,0.9303 \\
0.0088)\end{array}$ & $((5,3),(5,4))$ & $\begin{array}{c}(36,81,0.9652 \\
0.0040)\end{array}$ & $((4,4),(5,4))$ & $\begin{array}{c}(102,114,0.9810, \\
0.0010)\end{array}$ \\
\hline$((4,3),(4,4))$ & $\begin{array}{c}(62,108,0.9645 \\
0.0074)\end{array}$ & $((4,3),(5,3))$ & $\begin{array}{c}(39,79,0.9971 \\
0.0020)\end{array}$ & $((2,5),(3,5))$ & $\begin{array}{c}(116,96,0.9862 \\
0.0097)\end{array}$ \\
\hline$((4,4),(4,5))$ & $\begin{array}{c}(52,96,0.9205 \\
0.0044)\end{array}$ & $((5,4),(5,5))$ & $\begin{array}{c}(36,93,0.9901 \\
0.0032)\end{array}$ & $((3,5),(4,5))$ & $\begin{array}{c}(31,113,0.9799 \\
0.0007)\end{array}$ \\
\hline$((5,0),(5,1))$ & $\begin{array}{c}(46,78,0.9306 \\
0.0093)\end{array}$ & $((3,4),(4,4))$ & $\begin{array}{c}(39,101,0.9891, \\
0.0042)\end{array}$ & $((4,5),(5,5))$ & $\begin{array}{c}(31,110,0.9270, \\
0.0004)\end{array}$ \\
\hline
\end{tabular}

experiments results are consistent with Lemma 2 proposed in Section 3.2.

\subsection{Results of Model I in Static Environments}

5.2.1. Optimal Route from Single Source Node to the Destination Node. Here we use different set of satisfaction levels of the secondary optimization objective $l_{t}$ to reflect different requirements for timeliness objective in decision-making. The optimal route $P^{*}$ and its corresponding appropriate vector of weighting coefficients $\left(\theta^{*}, \eta^{*}\right)$ can be obtained by applying the static heuristic algorithm in Section 4.1. From Table 2 we can see that $P^{*}$ is the shortest path of the safety objective in Model I when $l_{t} \geq 7.2291$, and the corresponding appropriate vector of weighting coefficients is $(1,0) . P^{*}$ is the shortest path of the timeliness objective in Model I when $l_{t}=6.1392$, and the corresponding appropriate vector of weighting coefficients is $(0,1)$. Model I has no solution when $l_{t}<6.1392 \mathrm{~min}$. So we can conclude that the results of the multiobjective route planning model will differ when $l_{t}$ is set differently. 
TABLE 2: Parameters and route planning result under satisfaction level of travel time along the route.

\begin{tabular}{|c|c|c|c|c|c|}
\hline Optimal route $P^{*}$ & $\left(\theta^{*}, \eta^{*}\right)$ & Travel time (min) & Route safety (\%) & $l_{t}(\min )$ & $l_{s}(\%)$ \\
\hline $\begin{array}{l}{[(0,0),(0,1),(0,2),(1,2),(1,3),} \\
(1,4),(2,4),(3,4),(4,4),(4,5), \\
(5,5)]\end{array}$ & $(1,0)$ & 7.2291 & 89.0278 & $\geq 7.2291$ & \\
\hline $\begin{array}{l}{[(0,0),(0,1),(0,2),(1,2),(1,3),} \\
(1,4),(2,4),(3,4),(3,5),(4,5), \\
(5,5)]\end{array}$ & $(0.74,0.26)$ & 7.0850 & 88.9501 & 7.2000 & \\
\hline $\begin{array}{l}{[(0,0),(1,0),(2,0),(2,1),(3,1),} \\
(3,2),(4,2),(4,3),(5,3),(5,4), \\
(5,5)]\end{array}$ & $(0.44,0.56)$ & 6.2042 & 87.1939 & 7.00 & \\
\hline $\begin{array}{l}{[(0,0),(1,0),(2,0),(2,1),(3,1),} \\
(3,2),(4,2),(4,3),(5,3),(5,4), \\
(5,5)]\end{array}$ & $(0.44,0.56)$ & 6.2042 & 87.1939 & 6.8000 & \\
\hline $\begin{array}{l}{[(0,0),(1,0),(2,0),(2,1),(3,1),} \\
(3,2),(4,2),(4,3),(5,3),(5,4), \\
(5,5)]\end{array}$ & $(0.44,0.56)$ & 6.2042 & 87.1939 & 6.6000 & 85 \\
\hline $\begin{array}{l}{[(0,0),(1,0),(2,0),(2,1),(3,1),} \\
(3,2),(4,2),(4,3),(5,3),(5,4), \\
(5,5)]\end{array}$ & $(0.44,0.56)$ & 6.2042 & 87.1939 & 6.4000 & \\
\hline $\begin{array}{l}{[(0,0),(0,1),(0,2),(1,2),(2,2),} \\
(3,2),(4,2),(4,3),(5,3),(5,4), \\
(5,5)]\end{array}$ & $(0.06,0.94)$ & 6.1845 & 86.7396 & 6.2000 & \\
\hline $\begin{array}{l}{[(0,0),(1,0),(1,1),(2,1),(3,1),} \\
(3,2),(4,2),(4,3),(5,3),(5,4), \\
(5,5)]\end{array}$ & $(0.04,0.96)$ & 6.1392 & 85.0263 & 6.1800 & \\
\hline $\begin{array}{l}{[(0,0),(1,0),(1,1),(2,1),(3,1),} \\
(3,2),(4,2),(4,3),(5,3),(5,4), \\
(5,5)]\end{array}$ & $(0,1)$ & 6.1392 & 85.0263 & 6.1392 & \\
\hline No solution & - & - & - & $<6.1392$ & \\
\hline
\end{tabular}

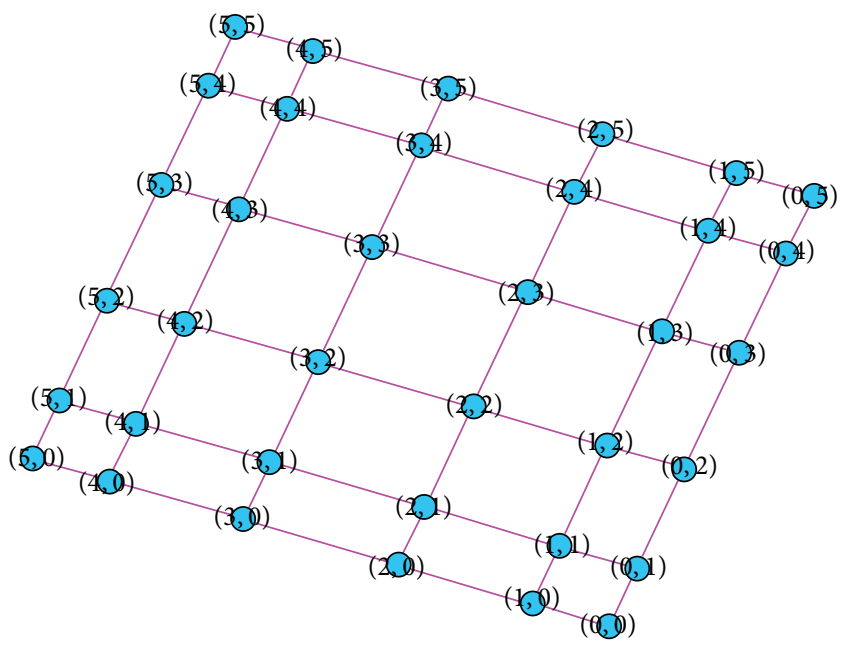

FIGURE 2: Structure of the emergency logistics network.

Figures 5 and 6 show the variations of route safety of $P^{*}$ and its corresponding appropriate weighting coefficients with the value of $l_{t}$, respectively. From Figure 5 we can see that the value of route safety along $P^{*}$ tends to decrease when $l_{t}$ becomes lower. This shows that the value of route safety through $P^{*}$ tends to decrease when we were more pressed for

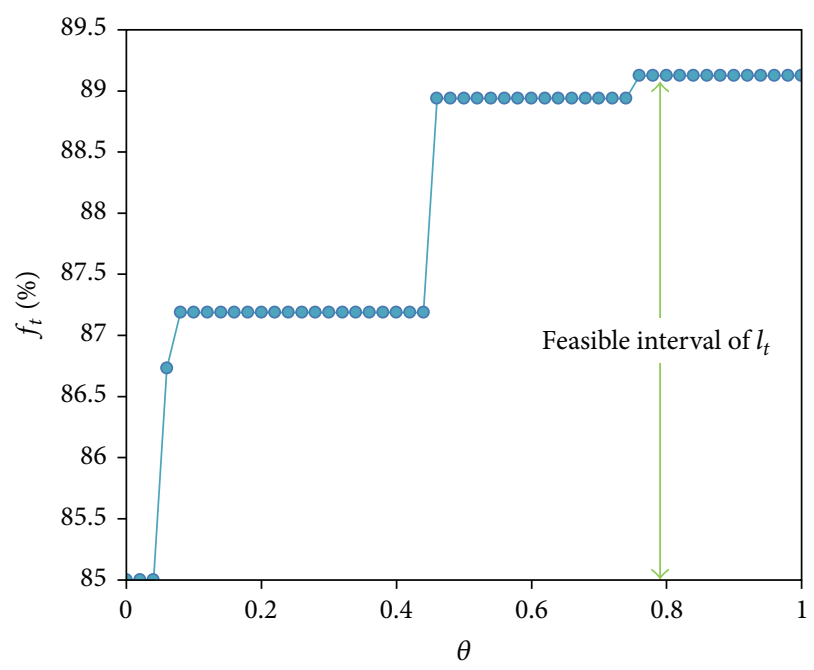

Figure 3: Variation of $f_{t}$ with the value of $\theta$.

time in finishing the emergency logistics tasks. From Figure 6 we can see that $\theta^{*}$ tends to increase and $\eta^{*}$ tends to decrease when the satisfaction level of the secondary optimization objective $l_{t}$ increases. We can see that appropriate weighting coefficients of timeliness optimization objective and safety optimization objective in the model tend to increase and 


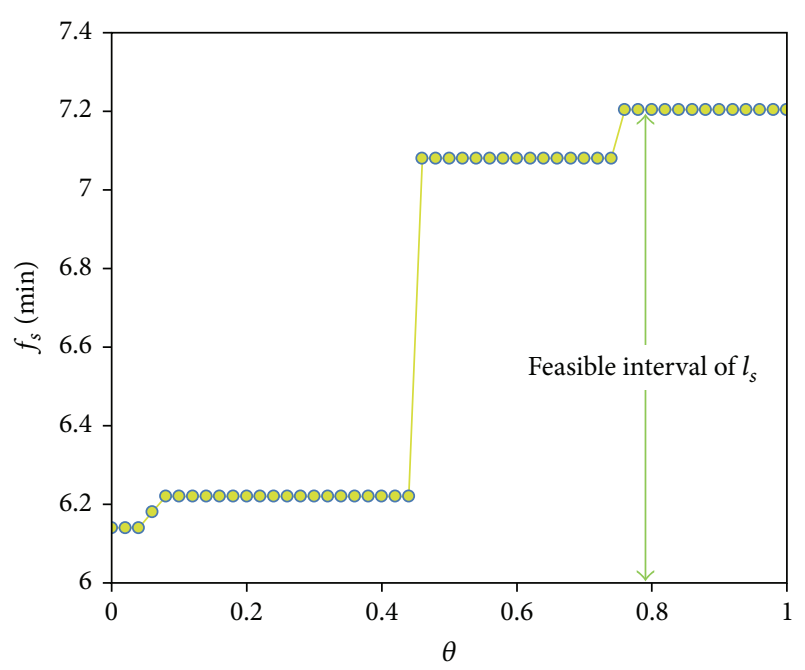

Figure 4: Variation of $f_{s}$ with the value of $\theta$.

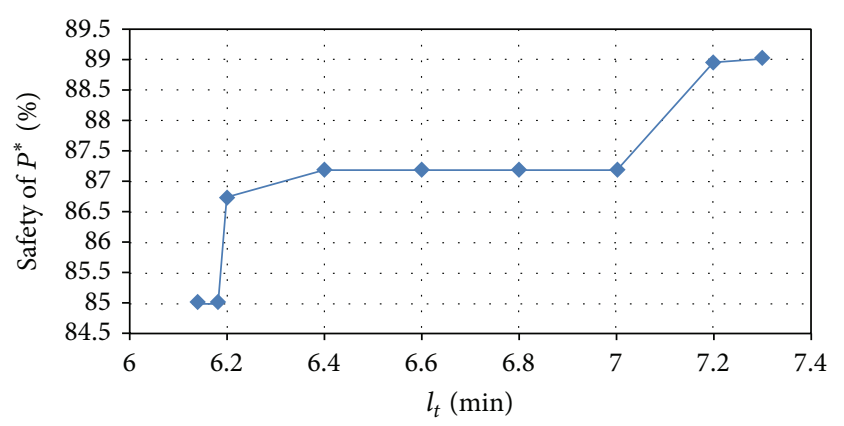

FIGURE 5: Variation of route safety of $P^{*}$ with the value of $l_{t}$.

decrease, respectively, when we were more pressed for time in finishing the emergency logistics tasks. This shows that the appropriate vector of weighting coefficients will be affected by the satisfaction level of policymakers.

Thus, the proposed static heuristic algorithm in Section 4.1 can be used as an auxiliary tool for emergency decisions, which can be used to assist emergency decisionmakers in finding the optimal route and reasonable weighting coefficients quickly.

5.2.2. Optimal Route from Multiple Source Nodes to the Destination Node. Different position of source nodes will affect the results of the multiobjective route planning model. Here we choose six different source nodes in the logistics network. Then let $l_{t}=6.14$ and keep it unchanged. Table 3 shows the optimal solutions to the multiobjective model from six different source nodes to the destination node. From the results shown in Table 3 , we can see that route safety through $P^{*}$ differs with the position of the source node.

Figure 7 shows the contrast of the route safety through $P^{*}$ obtained by the multiobjective model from six different source nodes to the destination node. From Figure 7 we can see that the route safety through the optimal route decreases with the travel time along the optimal route, that is, with

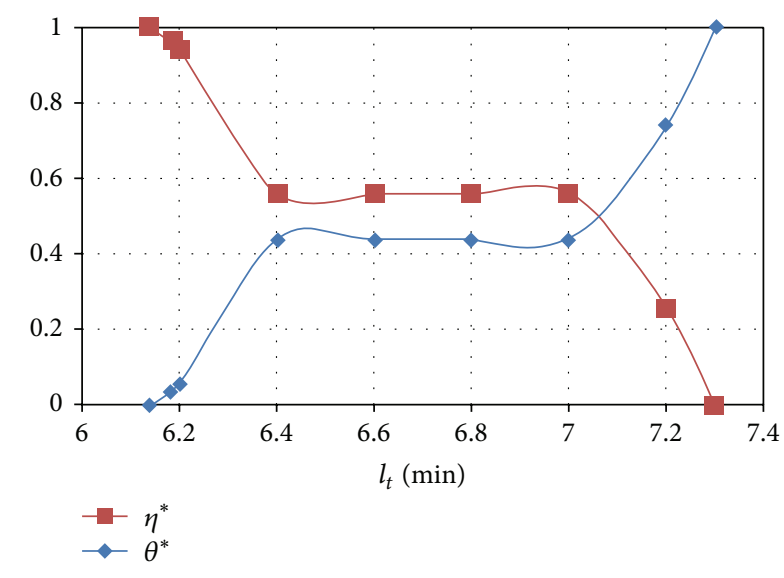

FIGURE 6: Variation of the corresponding appropriate weighting coefficients with the value of $l_{t}$.

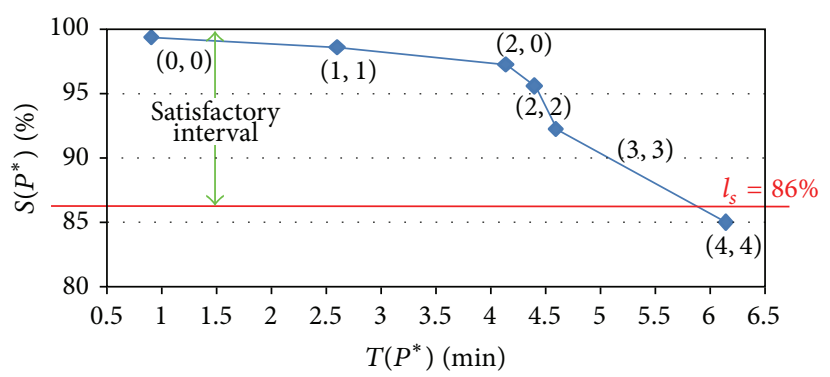

FIGURE 7: Variation of route safety along the optimal route with $T\left(P^{*}\right)$.

the distance from the source node to the destination node. Suppose $l_{s}=86 \%$; according to Figure 7 , we can see that there will be no optimal solution to the multiobjective model in compliance with the satisfactory level of policymakers if the source node is at the position of node $(4,4)$. The risk mitigation measures should be taken in the affected area of node $(4,4)$ to raise the safety of emergency logistics. Thus, the proposed algorithm in Section 4.1 can be used as an auxiliary tool for emergency decisions.

5.2.3. Results of the Route Planning Model under Different Extent of Disasters. Different extent of disasters will affect the travel condition on the arcs of the logistics network differently. Here we use different set of the congestion coefficient $\xi_{i j}$ and route safety of $\operatorname{arc}\left(v_{i}, v_{j}\right) s_{i j}$ to reflect the extent of disasters. $\xi_{i j}$ and $s_{i j}$ can reflect the instantaneous influence of disasters on the travel conditions of the arcs; littler $\xi_{i j}$ and $s_{i j}$ mean greater influence of disasters, respectively. Furthermore, different set of $\xi_{i j}$ and $s_{i j}$ can also reflect the influence of disasters on arcs in different positions.

In order to carry out our computational experiments under different extent of disasters, first we divide the logistics network with 36 nodes into three areas, the division of the network is shown in Figure 8, and arcs travelled through the boundary of two areas are treated as arcs in the former area. In each area values of $\xi_{i j}$ and $s_{i j}$ are generated randomly in 
TABLE 3: Parameters and route planning result with different set of source nodes.

\begin{tabular}{|c|c|c|c|c|c|}
\hline Source node & Destination node & Optimal route $P^{*}$ & Travel time/min & Route safety/\% & $l_{t}(\min )$ \\
\hline$(0,0)$ & $(5,5)$ & $\begin{array}{c}{[(0,0),(1,0),(1,1),(2,1),(3,1)} \\
(3,2),(4,2),(4,3),(5,3),(5,4) \\
(5,5)]\end{array}$ & 6.1392 & 85.0263 & \multirow{6}{*}{6.1400} \\
\hline$(1,1)$ & $(5,5)$ & $\begin{array}{l}{[(1,1),(2,1),(3,1),(3,2),(4,2)} \\
\quad(4,3),(5,3),(5,4),(5,5)]\end{array}$ & 4.5894 & 92.3785 & \\
\hline$(2,0)$ & $(5,5)$ & $\begin{array}{l}{[(2,0),(2,1),(3,1),(3,2),(4,2)} \\
\quad(5,2),(5,3),(5,4),(5,5)]\end{array}$ & 4.3956 & 95.6501 & \\
\hline$(2,2)$ & $(5,5)$ & $\begin{array}{c}{[(2,2),(2,3),(2,4),(3,4),(4,4)} \\
(4,5),(5,5)]\end{array}$ & 4.1354 & 97.4097 & \\
\hline$(3,3)$ & $(5,5)$ & {$[(3,3),(3,4),(4,4),(4,5),(5,5)]$} & 2.5987 & 98.7117 & \\
\hline$(4,4)$ & $(5,5)$ & {$[(4,4),(4,5),(5,5)]$} & 0.8963 & 99.5248 & \\
\hline
\end{tabular}

TABLE 4: Interval of route safety and travel speed decrease parameters under different disaster grades.

\begin{tabular}{lccc}
\hline Disaster grade & Area I & Area II & Area III \\
\hline 0 & $\xi=1, q=1$ & $\xi=1, q=1$ & $\xi=1, q=1$ \\
1 & $\xi \in(0.9,1.0), q \in(0.95,1.0)$ & $\xi=1, q \in(0.9,1.0)$ & $\xi=1, q=1$ \\
2 & $\xi \in(0.8,0.9), q \in(0.90,0.95)$ & $\xi \in(0.9,1.0), q \in(0.95,1.0)$ & $\xi=1, q \in(0.9,1.0)$ \\
3 & $\xi \in(0.7,0.8), q \in(0.85,0.90)$ & $\xi \in(0.8,0.9), q \in(0.90,0.95)$ & $\xi \in(0.9,1.0), q \in(0.95,1.0)$ \\
4 & $\xi \in(0.6,0.7), q \in(0.80,0.85)$ & $\xi \in(0.7,0.8), q \in(0.85,0.90)$ & $\xi \in(0.8,0.9), q \in(0.90,0.95)$ \\
5 & $\xi \in(0.5,0.6), q \in(0.75,0.80)$ & $\xi \in(0.6,0.7), q \in(0.80,0.85)$ & $\xi \in(0.7,0.8), q \in(0.85,0.90)$ \\
\hline
\end{tabular}

TABle 5: Parameters and route planning result under disaster grade 1.

\begin{tabular}{|c|c|c|c|c|c|c|}
\hline Area & $\left(v_{i}, v_{j}\right)$ & $\left(\xi_{i j},\left|\ln q_{i j}\right|\right)(-,-)$ & $\left(v_{i}, v_{j}\right)$ & $\left(\xi_{i j},\left|\ln q_{i j}\right|\right)(-,-)$ & $\left(v_{i}, v_{j}\right)$ & $\left(\xi_{i j},\left|\ln q_{i j}\right|\right)(-,-)$ \\
\hline \multirow{3}{*}{ I } & $((0,0),(0,1))$ & $(0.9648,0.0052)$ & $((1,0),(2,0))$ & $(0.9361,0.0046)$ & $((1,0),(1,1))$ & $(0.9286,0.00002)$ \\
\hline & $((0,0),(1,0))$ & $(0.9862,0.0037)$ & $((0,1),(1,1))$ & $(0.9351,0.0077)$ & $((1,1),(1,2))$ & $(0.9432,0.0002)$ \\
\hline & $((0,1),(0,2))$ & $(0.9029,0.0013)$ & $((1,1),(2,1))$ & $(0.9514,0.0099)$ & & \\
\hline \multirow{5}{*}{ II } & $((1,2),(1,3))$ & $(1,0)$ & $((2,0),(3,0))$ & $(1,0)$ & $((3,0),(3,1))$ & $(1,0)$ \\
\hline & $((0,3),(1,3))$ & $(1,0)$ & $((2,1),(3,1))$ & $(1,0)$ & $((3,0),(4,0))$ & $(1,0)$ \\
\hline & $((2,0),(2,1))$ & $(1,0)$ & $((0,2),(1,2))$ & $(1,0)$ & $((2,1),(2,2))$ & $(1,0)$ \\
\hline & $((0,2),(0,3))$ & $(1,0)$ & $((1,2),(2,2))$ & $(1,0)$ & & \\
\hline & $((2,2),(2,3))$ & $(1,0)$ & $((2,2),(3,2))$ & $(1,0)$ & & \\
\hline \multirow{13}{*}{ III } & $((0,3),(0,4))$ & $(1,0)$ & $((5,1),(5,2))$ & $(1,0)$ & $((4,2),(5,2))$ & $(1,0)$ \\
\hline & $((0,4),(0,5))$ & $(1,0)$ & $((4,0),(4,1))$ & $(1,0)$ & $((1,3),(2,3))$ & $(1,0)$ \\
\hline & $((1,4),(1,5))$ & $(1,0)$ & $((4,1),(4,2))$ & $(1,0)$ & $((2,3),(3,3))$ & $(1,0)$ \\
\hline & $((1,3),(1,4))$ & $(1,0)$ & $((4,2),(4,3))$ & $(1,0)$ & $((3,3),(4,3))$ & $(1,0)$ \\
\hline & $((2,3),(2,4))$ & $(1,0)$ & $((4,0),(5,0))$ & $(1,0)$ & $((0,4),(1,4))$ & $(1,0)$ \\
\hline & $((2,4),(2,5))$ & $(1,0)$ & $((3,1),(4,1))$ & $(1,0)$ & $((1,4),(2,4))$ & $(1,0)$ \\
\hline & $((3,1),(3,2))$ & $(1,0)$ & $((4,1),(5,1))$ & $(1,0)$ & $((2,4),(3,4))$ & $(1,0)$ \\
\hline & $((3,2),(3,3))$ & $(1,0)$ & $((3,2),(4,2))$ & $(1,0)$ & $((0,5),(1,5))$ & $(1,0)$ \\
\hline & $((3,3),(3,4))$ & $(1,0)$ & $((5,2),(5,3))$ & $(1,0)$ & $((1,5),(2,5))$ & $(1,0)$ \\
\hline & $((3,4),(3,5))$ & $(1,0)$ & $((5,3),(5,4))$ & $(1,0)$ & $((4,4),(5,4))$ & $(1,0)$ \\
\hline & $((4,3),(4,4))$ & $(1,0)$ & $((4,3),(5,3))$ & $(1,0)$ & $((2,5),(3,5))$ & $(1,0)$ \\
\hline & $((4,4),(4,5))$ & $(1,0)$ & $((5,4),(5,5))$ & $(1,0)$ & $((3,5),(4,5))$ & $(1,0)$ \\
\hline & $((5,0),(5,1))$ & $(1,0)$ & $((3,4),(4,4))$ & $(1,0)$ & $((4,5),(5,5))$ & $(1,0)$ \\
\hline \multirow{3}{*}{\multicolumn{2}{|c|}{ Optimum route }} & \multirow{3}{*}{\multicolumn{3}{|c|}{$[(0,0),(1,0),(1,1),(1,2),(2,2),(3,2),(4,2),(4,3),(5,3),(5,4),(5,5)]$}} & $\theta^{*}$ & 0.96 \\
\hline & & & & & Travel time & $6.0358656 \mathrm{~min}$ \\
\hline & & & & & Route safety & $99.6117325 \%$ \\
\hline
\end{tabular}




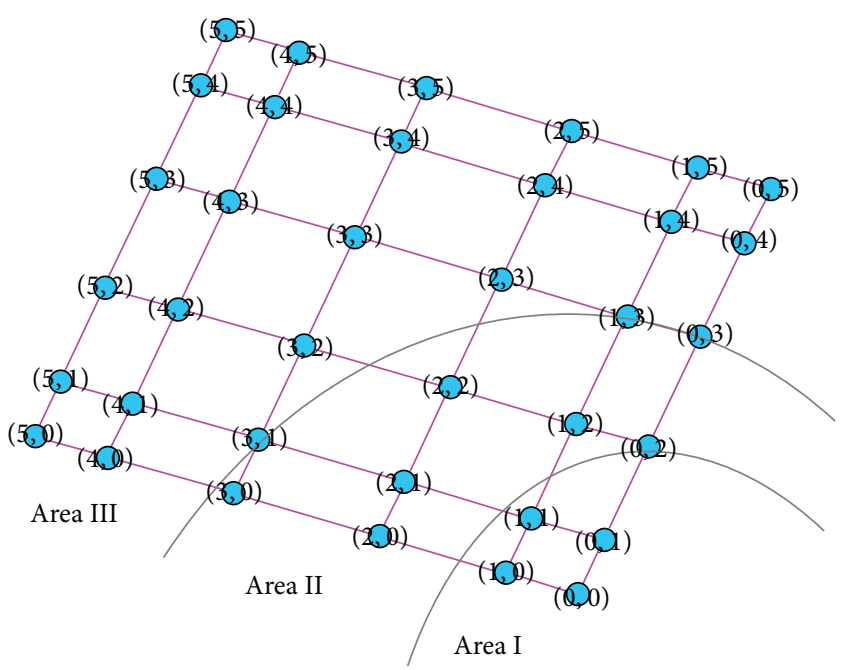

FIGURE 8: Structure of the emergency logistics network and its division.

TABLE 6: Parameters and route planning result under disaster grade 2.

\begin{tabular}{|c|c|c|c|c|c|c|}
\hline Area & $\left(v_{i}, v_{j}\right)$ & $\left(\xi_{i j},\left|\ln q_{i j}\right|\right)(-,-)$ & $\left(v_{i}, v_{j}\right)$ & $\left(\xi_{i j},\left|\ln q_{i j}\right|\right)(-,-)$ & $\left(v_{i}, v_{j}\right)$ & $\left(\xi_{i j},\left|\ln q_{i j}\right|\right)(-,-)$ \\
\hline \multirow{3}{*}{$\mathrm{I}$} & $((0,0),(0,1))$ & $(0.8606,0.0194)$ & $((1,0),(2,0))$ & $(0.8811,0.0226)$ & $((1,0),(1,1))$ & $(0.8735,0.0160)$ \\
\hline & $((0,0),(1,0))$ & $(0.8652,0.0235)$ & $((0,1),(1,1))$ & $(0.8428,0.0250)$ & $((1,1),(1,2))$ & $(0.8332,0.0211)$ \\
\hline & $((0,1),(0,2))$ & $(0.8306,0.0116)$ & $((1,1),(2,1))$ & $(0.8898,0.0141)$ & & \\
\hline \multirow{5}{*}{ II } & $((2,0),(3,0))$ & $(0.9091,0.0002)$ & $((0,2),(0,3))$ & $(0.9144,0.0097)$ & $((3,0),(3,1))$ & $(0.9110,0.0023)$ \\
\hline & $((2,1),(3,1))$ & $(0.9381,0.0065)$ & $((2,2),(2,3))$ & $(0.9865,0.0043)$ & $((3,0),(4,0))$ & $(0.9302,0.0030)$ \\
\hline & $((0,2),(1,2))$ & $(0.9985,0.0043)$ & $((1,2),(1,3))$ & $(0.9317,0.0099)$ & $((2,1),(2,2))$ & $(0.9572,0.0080)$ \\
\hline & $((1,2),(2,2))$ & $(0.9024,0.0077)$ & $((0,3),(1,3))$ & $(0.9205,0.0089)$ & & \\
\hline & $((2,2),(3,2))$ & $(1,0)$ & $((2,0),(2,1))$ & $(0.9352,0.0062)$ & & \\
\hline \multirow{13}{*}{ III } & $((0,3),(0,4))$ & $(1,0)$ & $((5,1),(5,2))$ & $(1,0)$ & $((3,5),(4,5))$ & $(1,0)$ \\
\hline & $((0,4),(0,5))$ & $(1,0)$ & $((4,0),(4,1))$ & $(1,0)$ & $((4,2),(5,2))$ & $(1,0)$ \\
\hline & $((1,4),(1,5))$ & $(1,0)$ & $((4,1),(4,2))$ & $(1,0)$ & $((1,3),(2,3))$ & $(1,0)$ \\
\hline & $((1,3),(1,4))$ & $(1,0)$ & $((4,2),(4,3))$ & $(1,0)$ & $((2,3),(3,3))$ & $(1,0)$ \\
\hline & $((2,3),(2,4))$ & $(1,0)$ & $((4,0),(5,0))$ & $(1,0)$ & $((3,3),(4,3))$ & $(1,0)$ \\
\hline & $((2,4),(2,5))$ & $(1,0)$ & $((3,1),(4,1))$ & $(1,0)$ & $((0,4),(1,4))$ & $(1,0)$ \\
\hline & $((3,1),(3,2))$ & $(1,0)$ & $((4,1),(5,1))$ & $(1,0)$ & $((1,4),(2,4))$ & $(1,0)$ \\
\hline & $((3,2),(3,3))$ & $(1,0)$ & $((3,2),(4,2))$ & $(1,0)$ & $((2,4),(3,4))$ & $(1,0)$ \\
\hline & $((3,3),(3,4))$ & $(1,0)$ & $((5,2),(5,3))$ & $(1,0)$ & $((0,5),(1,5))$ & $(1,0)$ \\
\hline & $((3,4),(3,5))$ & $(1,0)$ & $((5,3),(5,4))$ & $(1,0)$ & $((1,5),(2,5))$ & $(1,0)$ \\
\hline & $((4,3),(4,4))$ & $(1,0)$ & $((4,3),(5,3))$ & () & $((4,5),(5,5))$ & $(1,0)$ \\
\hline & $((4,4),(4,5))$ & $(1,0)$ & $((5,4),(5,5))$ & $(1,0)$ & $((4,4),(5,4))$ & $(1,0)$ \\
\hline & $((5,0),(5,1))$ & $(1,0)$ & $((3,4),(4,4))$ & () & $((2,5),(3,5))$ & $(1,0)$ \\
\hline \multirow{3}{*}{\multicolumn{2}{|c|}{ Optimum route }} & \multirow{3}{*}{\multicolumn{3}{|c|}{$[(0,0),(0,1),(0,2),(0,3),(0,4),(0,5),(1,5),(2,5),(3,5),(4,5),(5,5)]$}} & $\theta$ & 1 \\
\hline & & & & & Travel time & $7.7491759 \mathrm{~min}$ \\
\hline & & & & & Route safety & $96.0087401 \%$ \\
\hline
\end{tabular}

different intervals. Suppose the source node and destination node are $(0,0)$ and $(5,5)$, respectively. Let $l_{t}=8.6 \mathrm{~min}$ and keep it unchanged. So we can get five grades of disasters severity as shown in Table 4 . In the data of Table $4, \xi_{i j}$ and $s_{i j}$ are set litter in higher disaster grade than in lower disaster grade in corresponding areas, respectively. Disaster grade 0 stands for the situation when there no disaster happened and then the multiobjective route planning model is a single-objective model with respect to the travel time, that is, an ordinary shortest path problem.

In Tables 5-9, the values of $\xi_{i j}$ and $s_{i j}$ and the optimal route obtained by the proposed algorithm in Section 4.1 are presented. From Tables 5-9 we can see that the result of route planning differs with the disaster grade, that is, with the set of $\xi_{i j}$ and $s_{i j}$. Figures 9 and 10 show the variations of $f_{t}$ and $f_{s}$ with the value of $\theta$ under all the disaster grades, and the 
TABLE 7: Parameters and route planning result under disaster grade 3.

\begin{tabular}{|c|c|c|c|c|c|c|}
\hline Area & $\left(v_{i}, v_{j}\right)$ & $\left(\xi_{i j},\left|\ln q_{i j}\right|\right)(-,-)$ & $\left(v_{i}, v_{j}\right)$ & $\left(\xi_{i j},\left|\ln q_{i j}\right|\right)(-,-)$ & $\left(v_{i}, v_{j}\right)$ & $\left(\xi_{i j},\left|\ln q_{i j}\right|\right)(-,-)$ \\
\hline \multirow{3}{*}{ I } & $((0,0),(0,1))$ & $(0.7058,0.0397)$ & $((1,0),(2,0))$ & $(0.7105,0.0435)$ & $((1,0),(1,1))$ & $(0.7731,0.0377)$ \\
\hline & $((0,0),(1,0))$ & $(0.7866,0.0453)$ & $((0,1),(1,1))$ & $(0.7742,0.0511)$ & $((1,1),(1,2))$ & $(0.7458,0.0379)$ \\
\hline & $((0,1),(0,2))$ & $(0.7779,0.0354)$ & $((1,1),(2,1))$ & $(0.7663,0.0458)$ & & \\
\hline \multirow{5}{*}{ II } & $((1,2),(1,3))$ & $(0.8372,0.0114)$ & $((2,0),(3,0))$ & $(0.8797,0.0251)$ & $((3,0),(3,1))$ & $(0.8429,0.0186)$ \\
\hline & $((0,3),(1,3))$ & $(0.8387,0.0211)$ & $((2,1),(3,1))$ & $(0.8941,0.0114)$ & $((3,0),(4,0))$ & $(0.8985,0.0133)$ \\
\hline & $((2,0),(2,1))$ & $(0.8105,0.0147)$ & $((0,2),(1,2))$ & $(0.8078,0.0175)$ & $((2,1),(2,2))$ & $(0.8665,0.0181)$ \\
\hline & $((0,2),(0,3))$ & $(0.8351,0.0212)$ & $((1,2),(2,2))$ & $(0.8996,0.0140)$ & & \\
\hline & $((2,2),(2,3))$ & $(0.8776,0.0145)$ & $((2,2),(3,2))$ & $(0.8290,0.0171)$ & & \\
\hline \multirow{13}{*}{ III } & $((0,3),(0,4))$ & $(0.9503,0.0099)$ & $((5,1),(5,2))$ & $(0.9245,0.0004)$ & $((4,2),(5,2))$ & $(0.9963,0.0020)$ \\
\hline & $((0,4),(0,5))$ & $(0.9363,0.0085)$ & $((4,0),(4,1))$ & $(0.9168,0.0019)$ & $((1,3),(2,3))$ & $(0.9922,0.0045)$ \\
\hline & $((1,4),(1,5))$ & $(0.9367,0.0033)$ & $((4,1),(4,2))$ & $(0.9364,0.0062)$ & $((2,3),(3,3))$ & $(0.9176,0.0051)$ \\
\hline & $((1,3),(1,4))$ & $(0.9941,0.0025)$ & $((4,2),(4,3))$ & $(0.9268,0.0079)$ & $((3,3),(4,3))$ & $(0.9842,0.0039)$ \\
\hline & $((2,3),(2,4))$ & $(0.9199,0.0027)$ & $((4,0),(5,0))$ & $(0.9425,0.0030)$ & $((0,4),(1,4))$ & $(0.9397,0.0037)$ \\
\hline & $((2,4),(2,5))$ & $(0.9167,0.0075)$ & $((3,1),(4,1))$ & $(0.9246,0.0080)$ & $((1,4),(2,4))$ & $(0.9657,0.0006)$ \\
\hline & $((3,1),(3,2))$ & $(0.9697,0.0036)$ & $((4,1),(5,1))$ & $(0.9967,0.0094)$ & $((2,4),(3,4))$ & $(0.9247,0.0001)$ \\
\hline & $((3,2),(3,3))$ & $(0.9295,0.0034)$ & $((3,2),(4,2))$ & $(0.9329,0.0014)$ & $((0,5),(1,5))$ & $(0.9320,0.0025)$ \\
\hline & $((3,3),(3,4))$ & $(0.9786,0.0040)$ & $((5,2),(5,3))$ & $(0.9247,0.0041)$ & $((1,5),(2,5))$ & $(0.9868,0.0034)$ \\
\hline & $((3,4),(3,5))$ & $(0.9303,0.0088)$ & $((5,3),(5,4))$ & $(0.9652,0.0040)$ & $((4,4),(5,4))$ & $(0.9810,0.0010)$ \\
\hline & $((4,3),(4,4))$ & $(0.9645,0.0074)$ & $((4,3),(5,3))$ & $(0.9971,0.0020)$ & $((2,5),(3,5))$ & $(0.9862,0.0097)$ \\
\hline & $((4,4),(4,5))$ & $(0.9205,0.0044)$ & $((5,4),(5,5))$ & $(0.9901,0.0032)$ & $((3,5),(4,5))$ & $(0.9799,0.0007)$ \\
\hline & $((5,0),(5,1))$ & $(0.9306,0.0093)$ & $((3,4),(4,4))$ & $(0.9891,0.0042)$ & $((4,5),(5,5))$ & $(0.9270,0.0004)$ \\
\hline \multirow{3}{*}{\multicolumn{2}{|c|}{ Optimum route }} & \multirow{3}{*}{\multicolumn{3}{|c|}{$[(0,0),(0,1),(0,2),(1,2),(1,3),(1,4),(2,4),(3,4),(4,4),(4,5),(5,5)]$}} & $\theta^{*}$ & 1 \\
\hline & & & & & Travel time & $7.2291308 \mathrm{~min}$ \\
\hline & & & & & Route safety & $89.0277776 \%$ \\
\hline
\end{tabular}

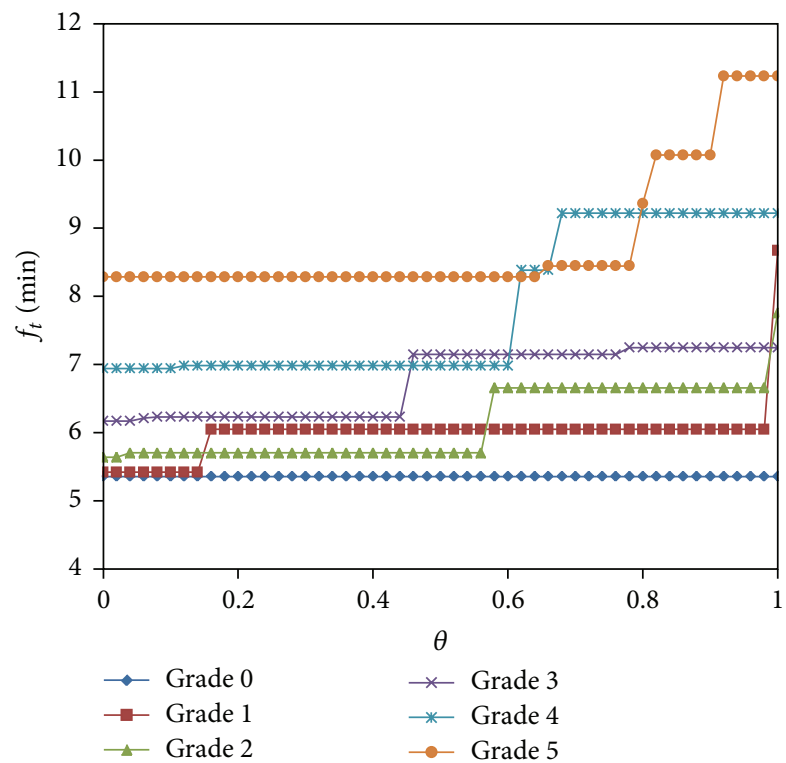

FIGURE 9: Variation of $f_{t}$ with the value of $\theta$ under different disaster grades.

interval of each two adjacent sets of $\theta$ is 0.02 . From Figures 9 and 10 we can see that the maximum and minimum values of $S\left(P^{*}\right)$ differ with the disaster grade.

Figure 11 shows values of route safety through the optimal route under all the disaster grades. From Figure 11 we can

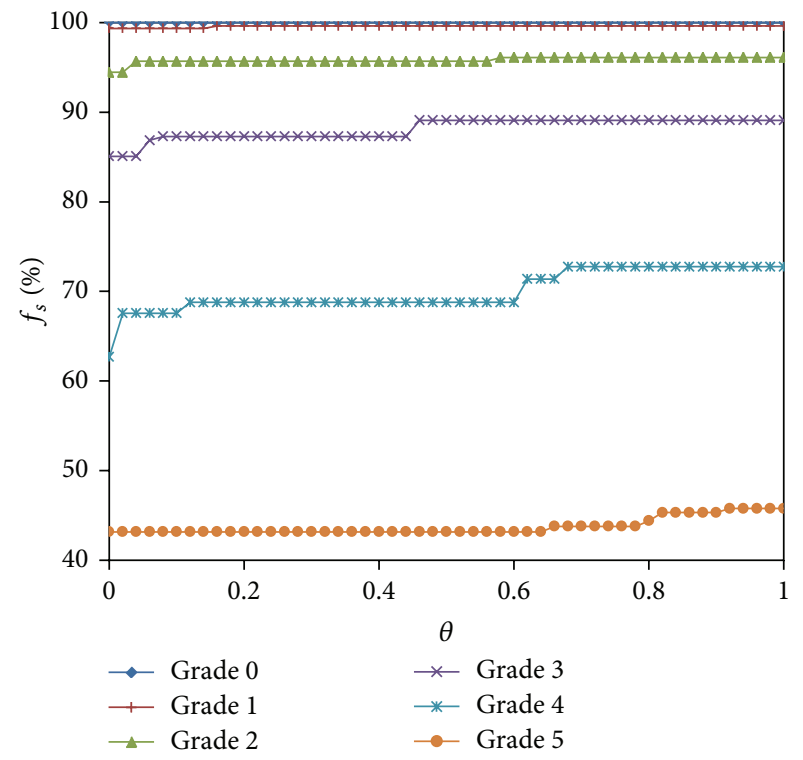

Figure 10: Variation of $f_{s}$ with the value of $\theta$ under different disaster grades.

see that the route safety through the optimal route decreases with the disaster grade. If we suppose $l_{s}=86 \%$, according to Figure 11, the emergency logistics activities on the ground are not safe and feasible if the disaster grade is higher than grade 3 , and therefore other logistics plans should be taken 
TABLE 8: Parameters and route planning result under disaster grade 4.

\begin{tabular}{|c|c|c|c|c|c|c|}
\hline Area & $\left(v_{i}, v_{j}\right)$ & $\left(\xi_{i j},\left|\ln q_{i j}\right|\right)(-,-)$ & $\left(v_{i}, v_{j}\right)$ & $\left(\xi_{i j},\left|\ln q_{i j}\right|\right)(-,-)$ & $\left(v_{i}, v_{j}\right)$ & $\left(\xi_{i j},\left|\ln q_{i j}\right|\right)(-,-)$ \\
\hline \multirow{3}{*}{ I } & $((0,0),(0,1))$ & $(0.6743,0.1132)$ & $((1,0),(2,0))$ & $(0.6920,0.1518)$ & $((1,0),(1,1))$ & $(0.6817,0.1610)$ \\
\hline & $((0,0),(1,0))$ & $(0.6219,0.1140)$ & $((0,1),(1,1))$ & $(0.6292,0.0551)$ & $((1,1),(1,2))$ & $(0.6119,0.0866)$ \\
\hline & $((0,1),(0,2))$ & $(0.6958,0.07189)$ & $((1,1),(2,1))$ & $(0.6621,0.1452)$ & & \\
\hline \multirow{5}{*}{ II } & $((2,0),(3,0))$ & $(0.7706,0.0280)$ & $((0,2),(0,3))$ & $(0.7723,0.0309)$ & $((2,2),(2,3))$ & $(0.7388,0.0420)$ \\
\hline & $((2,2),(3,2))$ & $(0.7817,0.0333)$ & $((1,2),(1,3))$ & $(0.7370,0.0511)$ & $((3,0),(3,1))$ & $(0.7851,0.0282)$ \\
\hline & $((2,1),(3,1))$ & $(0.7920,0.0490)$ & $((0,3),(1,3))$ & $(0.7274,0.0430)$ & $((3,0),(4,0))$ & $(0.7849,0.0411)$ \\
\hline & $((0,2),(1,2))$ & $(0.7615,0.0492)$ & $((2,0),(2,1))$ & $(0.7145,0.0477)$ & & \\
\hline & $((1,2),(2,2))$ & $(0.7252,0.0292)$ & $((2,1),(2,2))$ & $(0.7820,0.0448)$ & & \\
\hline \multirow{13}{*}{ III } & $((0,3),(0,4))$ & $(0.8396,0.0101)$ & $((4,0),(4,1))$ & $(0.8920,0.0205)$ & $((4,2),(5,2))$ & $(0.8680,0.0194)$ \\
\hline & $((0,4),(0,5))$ & $(0.8414,0.0168)$ & $((4,1),(4,2))$ & $(0.8093,0.0195)$ & $((1,3),(2,3))$ & $(0.9419,0.0219)$ \\
\hline & $((1,4),(1,5))$ & $(0.8128,0.0222)$ & $((4,2),(4,3))$ & $(0.8810,0.0105)$ & $((2,3),(3,3))$ & $(0.8927,0.0240)$ \\
\hline & $((1,3),(1,4))$ & $(0.8397,0.0167)$ & $((5,1),(5,2))$ & $(0.8632,0.0191)$ & $((3,3),(4,3))$ & $(0.8858,0.0109)$ \\
\hline & $((2,3),(2,4))$ & $(0.8786,0.0134)$ & $((4,0),(5,0))$ & $(0.8152,0.0245)$ & $((0,4),(1,4))$ & $(0.8255,0.0243)$ \\
\hline & $((2,4),(2,5))$ & $(0.8341,0.0221)$ & $((3,1),(4,1))$ & $(0.8522,0.0185)$ & $((1,4),(2,4))$ & $(0.8277,0.0236)$ \\
\hline & $((3,1),(3,2))$ & $(0.8784,0.0122)$ & $((4,1),(5,1))$ & $(0.8403,0.0109)$ & $((2,4),(3,4))$ & $(0.8986,0.0216)$ \\
\hline & $((3,2),(3,3))$ & $(0.8285,0.0201761187147)$ & $((3,2),(4,2))$ & $(0.8255,0.0218)$ & $((0,5),(1,5))$ & $(0.8282,0.0117)$ \\
\hline & $((3,3),(3,4))$ & $(0.8751,0.0237)$ & $((5,2),(5,3))$ & $(0.8360,0.0209)$ & $((1,5),(2,5))$ & $(0.8503,0.0103)$ \\
\hline & $((3,4),(3,5))$ & $(0.8133,0.0192)$ & $((5,3),(5,4))$ & $(0.8803,0.0239)$ & $((4,5),(5,5))$ & $(0.8248,0.0247)$ \\
\hline & $((4,3),(4,4))$ & $(0.8414,0.0131)$ & $((4,3),(5,3))$ & $(0.8407,0.0232)$ & $((4,4),(5,4))$ & $(0.8083,0.0168)$ \\
\hline & $((4,4),(4,5))$ & $(0.8674,0.0106)$ & $((5,4),(5,5))$ & $(0.8048,0.0181)$ & $((2,5),(3,5))$ & $(0.8897,0.0162)$ \\
\hline & $((5,0),(5,1))$ & $(0.8122,0.0241)$ & $((3,4),(4,4))$ & $(0.8740,0.0204)$ & $((3,5),(4,5))$ & $(0.8867,0.0146)$ \\
\hline \multirow{3}{*}{\multicolumn{2}{|c|}{ Optimum route }} & \multirow{3}{*}{\multicolumn{3}{|c|}{$[(0,0),(0,1),(0,2),(0,3),(0,4),(1,4),(1,5),(2,5),(3,5),(4,5),(5,5)]$}} & $\theta^{*}$ & 0.66 \\
\hline & & & & & Travel time & $8.3728390 \mathrm{~min}$ \\
\hline & & & & & Route safety & $71.2934663 \%$ \\
\hline
\end{tabular}

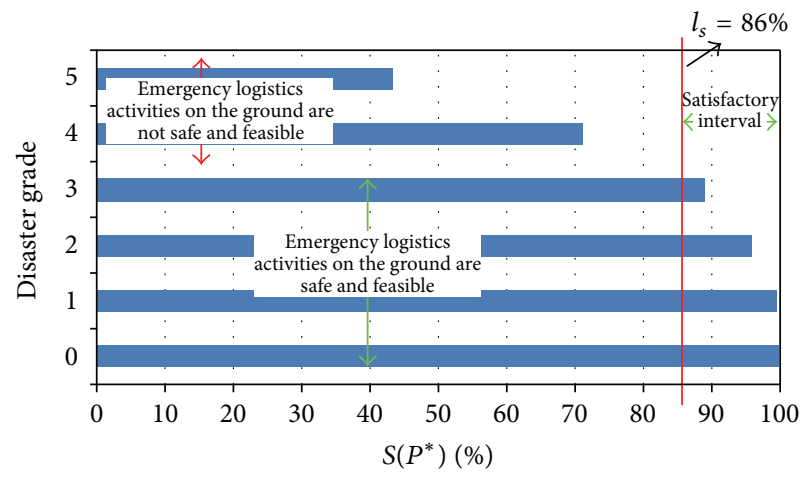

FigURE 11: Route safety through the optimum route $P^{*}$ under different disaster grades.

in the emergency response activities. Thus, the proposed algorithm in Section 4.1 can be used as an auxiliary tool for emergency decisions.

5.3. Results of Model I in Dynamic Environments. When the period of logistics operation is long, the congestion coefficient $\xi_{i j}$ and route safety of $\operatorname{arc}\left(v_{i}, v_{j}\right) s_{i j}$ will be dynamically changed in route planning problem for emergency logistics management under real-time effect of disaster extension, so the travel time $t_{i j}$ on $\operatorname{arc}\left(v_{i}, v_{j}\right)$ is determined not only by the length of the arc $l_{i j}$ and the travel speed function $u_{i j}(t)$, but also by the time when the logistics reach the origin node $v_{i}$ of $\operatorname{arc}\left(v_{i}, v_{j}\right)$ since the travel speed on each arc is dynamic with time. For the same reason, route safety of $\operatorname{arc}\left(v_{i}, v_{j}\right) s_{i j}$ is also determined by the time when the logistics reach the origin node $v_{i}$ of $\operatorname{arc}\left(v_{i}, v_{j}\right)$.

Here the source node is $(0,0)$ and the destination node is $(5,5)$. Meanwhile let $l_{t}=10$ and keep it unchanged. Then we use different set of the values of time $t_{0}$ when the logistics reach the source node $v_{0}$ to reflect the response time of emergency logistics. In Table 10 , the optimal route $P^{*}$ in dynamic environments obtained by the proposed algorithm in Section 4.2 is presented.

From Table 10 we can see that the result of route planning differs with different set of values of $t_{0}$. Figure 12 shows values of route safety through the optimal route corresponding to different set of values of $t_{0}$. From Figure 12 we can see that the route safety through the optimal route decreases with $t_{0}$, that is, with the response time of emergency logistics.

Suppose $l_{s}=86 \%$; according to Figure 12 , there will be no optimal solution to the multiobjective model in compliance with the satisfactory level of policymakers if $t_{0} \geq 12$. So it is necessary to respond timely so that certain tasks can be executed before the disaster becomes more serious.

Based on Figure 12, the policymakers can easily decide a reasonable response time for the emergency logistics activities. Thus, the proposed algorithm in Section 4.2 can be used as an auxiliary tool for emergency decisions. 
TABLE 9: Parameters and route planning result under disaster grade 5.

\begin{tabular}{|c|c|c|c|c|c|c|}
\hline Area & $\left(v_{i}, v_{j}\right)$ & $\left(\xi_{i j},\left|\ln q_{i j}\right|\right)(-,-)$ & $\left(v_{i}, v_{j}\right)$ & $\left(\xi_{i j},\left|\ln q_{i j}\right|\right)(-,-)$ & $\left(v_{i}, v_{j}\right)$ & $\left(\xi_{i j},\left|\ln q_{i j}\right|\right)(-,-)$ \\
\hline \multirow{3}{*}{ I } & $((0,0),(0,1))$ & $(0.7058,0.0397)$ & $((1,0),(2,0))$ & $(0.7105,0.0436)$ & $((1,0),(1,1))$ & $((1,0),(1,1))$ \\
\hline & $((0,0),(1,0))$ & $(0.7866,0.0453)$ & $((0,1),(1,1))$ & $(0.7742,0.0511)$ & $((1,1),(1,2))$ & $((1,1),(1,2))$ \\
\hline & $((0,1),(0,2))$ & $(0.7779,0.0354)$ & $((1,1),(2,1))$ & $(0.7663,0.0458)$ & & \\
\hline \multirow{5}{*}{ II } & $((0,3),(1,3))$ & $(0.8387,0.0211)$ & $((2,2),(2,3))$ & $(0.8776,0.0145)$ & $((3,0),(3,1))$ & $(0.8429,0.0186)$ \\
\hline & $((2,0),(3,0))$ & $(0.8797,0.0251)$ & $((1,2),(1,3))$ & $(0.8372,0.0114)$ & $((3,0),(4,0))$ & $(0.8985,0.0133)$ \\
\hline & $((2,1),(3,1))$ & $(0.8941,0.0114)$ & $((0,2),(0,3))$ & $(0.8351,0.0212)$ & $((2,2),(3,2))$ & $(0.8290,0.0171)$ \\
\hline & $((0,2),(1,2))$ & $(0.8078,0.0175)$ & $((2,0),(2,1))$ & $(0.8105,0.0147)$ & & \\
\hline & $((1,2),(2,2))$ & $(0.8996,0.0140)$ & $((2,1),(2,2))$ & $(0.8665,0.0181)$ & & \\
\hline \multirow{13}{*}{ III } & $((0,4),(0,5))$ & $(0.9363,0.0085)$ & $((4,0),(4,1))$ & $(0.9168,0.0019)$ & $((4,2),(5,2))$ & $(0.9963,0.0020)$ \\
\hline & $((1,4),(1,5))$ & $(0.9367,0.0033)$ & $((4,1),(4,2))$ & $(0.9364,0.0062)$ & $((1,3),(2,3))$ & $(0.9922,0.0045)$ \\
\hline & $((1,3),(1,4))$ & $(0.9941,0.0025)$ & $((4,2),(4,3))$ & $(0.9268,0.0079)$ & $((2,3),(3,3))$ & $(0.9176,0.0051)$ \\
\hline & $((0,3),(0,4))$ & $(0.9503,0.0099)$ & $((3,4),(4,4))$ & $(0.9891,0.0042)$ & $((3,3),(4,3))$ & $(0.9842,0.0039)$ \\
\hline & $((2,3),(2,4))$ & $(0.9199,0.0026)$ & $((4,0),(5,0))$ & $(0.9425,0.0030)$ & $((0,4),(1,4))$ & $(0.9397,0.0037)$ \\
\hline & $((2,4),(2,5))$ & $(0.9167,0.0075)$ & $((3,1),(4,1))$ & $(0.9246,0.0080)$ & $((1,4),(2,4))$ & $(0.9657,0.0006)$ \\
\hline & $((3,1),(3,2))$ & $(0.9697,0.0036)$ & $((4,1),(5,1))$ & $(0.9967,0.0094)$ & $((2,4),(3,4))$ & $(0.9247,0.0001)$ \\
\hline & $((3,2),(3,3))$ & $(0.9295,0.0034)$ & $((5,1),(5,2))$ & $(0.9245,0.0004)$ & $((0,5),(1,5))$ & $(0.9320,0.0025)$ \\
\hline & $((3,3),(3,4))$ & $(0.9786,0.0040)$ & $((3,2),(4,2))$ & $(0.9329,0.0014)$ & $((1,5),(2,5))$ & $(0.9868,0.0034)$ \\
\hline & $((3,4),(3,5))$ & $(0.9303,0.0088)$ & $((5,2),(5,3))$ & $(0.9247,0.0041)$ & $((4,5),(5,5))$ & $(0.9270,0.0004)$ \\
\hline & $((4,3),(4,4))$ & $(0.9645,0.0074)$ & $((5,3),(5,4))$ & $(0.9652,0.0040)$ & $(((4,4),(5,4))$ & $(0.9810,0.0100)$ \\
\hline & $((4,4),(4,5))$ & $(0.9205,0.0044)$ & $((5,2),(5,3))$ & $(0.9247,0.0041)$ & $((2,5),(3,5))$ & $(0.9862,0.0097)$ \\
\hline & $((5,0),(5,1))$ & $(0.9306,0.0093)$ & $((4,3),(5,3))$ & $(0.9971,0.0020)$ & $((3,5),(4,5))$ & $(0.9798,0.0007)$ \\
\hline \multirow{3}{*}{\multicolumn{2}{|c|}{ Optimum route }} & \multirow{3}{*}{\multicolumn{3}{|c|}{$[(0,0),(1,0),(2,0),(2,1),(3,1),(4,1),(4,2),(4,3),(5,3),(5,4),(5,5)]$}} & $\theta^{*}$ & 0.76 \\
\hline & & & & & Travel time & $8.4277602 \mathrm{~min}$ \\
\hline & & & & & Route safety & $43.4060687 \%$ \\
\hline
\end{tabular}

TABLE 10: Interval of congestion coefficient and route safety at different times and route planning result with different starting time.

\begin{tabular}{|c|c|c|c|c|c|}
\hline \multirow{4}{*}{$\begin{array}{l}\left(\xi_{i j},\left|\ln q_{i j}\right|\right)(-,-) \\
t_{0} / \mathrm{min}\end{array}$} & \multicolumn{5}{|c|}{ Time interval } \\
\hline & \multirow{3}{*}{$\begin{array}{c}{[0,5)} \\
\text { See Table } 5 \\
\text { Route id }\end{array}$} & \multirow{3}{*}{$\begin{array}{c}\qquad 10,15) \\
\text { See Table } 7 \\
\text { Optimal route }\end{array}$} & \multirow{2}{*}{\multicolumn{2}{|c|}{$\begin{array}{c}{[15,20)} \\
\text { See Table } 8\end{array}$}} & \multirow{3}{*}{$\begin{array}{c}{[20,25)} \\
\text { See Table } 9 \\
l_{t}(\min )\end{array}$} \\
\hline & & & & & \\
\hline & & & Travel time (min) & Route safety $(-)$ & \\
\hline 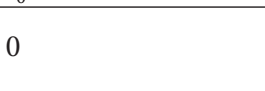 & $P_{0}$ & $\begin{array}{l}{[(0,0),(1,0),(1,1),(1,2),(0,2),(0,3),(0,} \\
4),(0,5),(1,5),(2,5),(3,5),(4,5),(5,5)]\end{array}$ & 8.670753 & 0.986905 & \\
\hline 3 & $P_{1}$ & $\begin{array}{l}{[(0,0),(1,0),(1,1),(1,2),(1,3),(1,4),(1,} \\
5),(2,5),(3,5),(4,5),(5,5)]\end{array}$ & 6.619152 & 0.981555 & \\
\hline 6 & $P_{2}$ & $\begin{array}{l}{[(0,0),(0,1),(0,2),(0,3),(0,4),(0,5),(1,} \\
5),(1,4),(2,4),(3,4),(4,4),(4,5),(5,5)]\end{array}$ & 9.126793 & 0.942204 & \\
\hline 9 & $P_{3}$ & $\begin{array}{l}{[(0,0),(0,1),(0,1),(0,2),(1,2),(1,3),(1,} \\
4),(2,4),(3,4),(4,4),(4,5),(5,5)]\end{array}$ & 7.009755 & 0.90845 & 10 \\
\hline 12 & $P_{4}$ & $\begin{array}{l}{[(0,0),(0,1),(0,2),(1,2),(1,3),(1,4),(1,} \\
5),(2,5),(3,5),(4,5),(5,5)]\end{array}$ & 7.990459 & 0.804204 & \\
\hline 15 & $P_{5}$ & $\begin{array}{l}{[(0,0),(0,1),(0,2),(0,3),(0,4),(0,5),(1,} \\
5),(2,5),(3,5),(4,5),(5,5)]\end{array}$ & 7.842856 & 0.632161 & \\
\hline
\end{tabular}

\section{Conclusions}

Route planning problem is an important issue in emergency management. A route planning model based on multiobjective optimization is presented in this paper. The safety of the path is modeled as the product of safety through arcs included in the path. Based on bounded rationality theory, a conditional multiobjective shortest path model was proposed. Finally, a numerical example has been presented to illustrate the effectiveness of the model. There still remain quite a lot of complex factors in route selection for emergency logistics management to be considered. Here we just take time and safety as the main factors in route section for emergency logistics management. Building route selection models taking more actual factors into account will be one of our future work directions. 


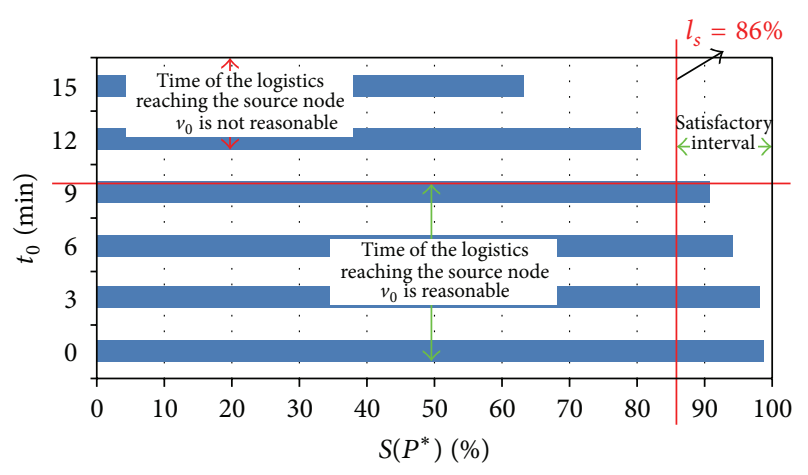

FIGURE 12: Route safety of $P^{*}$ under different set of values of $t_{0}$.

\section{Conflict of Interests}

The authors declare that there is no conflict of interests regarding the publication of this paper.

\section{Acknowledgments}

The work described in this paper is partially supported by the National Natural Science Foundation of China, Grant nos. 71173198, 91324017, and 71103162, the National Science and Technology Support Program of China, Grant nos. 2012BAK03B05 and 2012BAK20B02, and the Fundamental Science Research Project of China Academy of Safety Science and Technology, Grant no. 2014JBKY02.

\section{References}

[1] H. Toya and M. Skidmore, "Economic development and the impacts of natural disasters," Economics Letters, vol. 94, no. 1, pp. 20-25, 2007.

[2] M.-S. Chang, Y.-L. Tseng, and J.-W. Chen, "A scenario planning approach for the flood emergency logistics preparation problem under uncertainty," Transportation Research Part E: Logistics and Transportation Review, vol. 43, no. 6, pp. 737-754, 2007.

[3] M. Skidmore and H. Toya, "Natural disaster impacts and fiscal decentralization," Land Economics, vol. 89, no. 1, pp. 101-117, 2013.

[4] Y. Deng and F. T. S. Chan, "A new fuzzy dempster MCDM method and its application in supplier selection," Expert Systems with Applications, vol. 38, no. 8, pp. 9854-9861, 2011.

[5] M. Gorge, "Crisis management best practice-where do we start from?” Computer Fraud and Security, vol. 2006, no. 6, pp. 10-13, 2006.

[6] B. Barlas, "Occupational fatalities in shipyards: an analysis in Turkey," Brodogradnja, vol. 63, no. 1, pp. 35-41, 2012.

[7] A. M. Caunhye, X. Nie, and S. Pokharel, "Optimization models in emergency logistics: a literature review," Socio-Economic Planning Sciences, vol. 46, no. 1, pp. 4-13, 2012.

[8] M. A. G. Bastos, V. B. G. Campos, and R. A. de Mello Bandeira, "Logistic processes in a post-disaster relief operation," Procedia-Social and Behavioral Sciences, vol. 111, pp. 1175-1184, 2014.

[9] W. Yi and L. Özdamar, "A dynamic logistics coordination model for evacuation and support in disaster response activities,"
European Journal of Operational Research, vol. 179, no. 3, pp. 1177-1193, 2007.

[10] L. Özdamar and O. Demir, "A hierarchical clustering and routing procedure for large scale disaster relief logistics planning," Transportation Research Part E: Logistics and Transportation Review, vol. 48, no. 3, pp. 591-602, 2012.

[11] J.-B. Sheu, "An emergency logistics distribution approach for quick response to urgent relief demand in disasters," Transportation Research Part E: Logistics and Transportation Review, vol. 43, no. 6, pp. 687-709, 2007.

[12] Z.-H. Hu, "A container multimodal transportation scheduling approach based on immune affinity model for emergency relief," Expert Systems with Applications, vol. 38, no. 3, pp. 2632-2639, 2011.

[13] D. Berkoune, J. Renaud, M. Rekik, and A. Ruiz, "Transportation in disaster response operations," Socio-Economic Planning Sciences, vol. 46, no. 1, pp. 23-32, 2012.

[14] S. J. Rennemo, K. F. Rø, L. M. Hvattum, and G. Tirado, "A three-stage stochastic facility routing model for disaster response planning," Transportation Research Part E: Logistics and Transportation Review, vol. 62, pp. 116-135, 2014.

[15] Y. Yuan and D. Wang, "Path selection model and algorithm for emergency logistics management," Computers \& Industrial Engineering, vol. 56, no. 3, pp. 1081-1094, 2009.

[16] X. Zhang, Z. Zhang, Y. Zhang, D. Wei, and Y. Deng, "Route selection for emergency logistics management: a bio-inspired algorithm," Safety Science, vol. 54, pp. 87-91, 2013.

[17] H. Yue, Research on Method to Solve Uncertain Optimization Problem Based on Interval Number, North China Electric Power University, 2013.

[18] Z. X. Wang, Y. G. Dang, and C. P. Song, "Multiobjective decision model of the grey situation based on interval number," Control and Decision, vol. 24, no. 3, pp. 388-392, 2009.

[19] B. D. Jones, "Bounded rationality and public policy: Herbert A. Simon and the decisional foundation of collective choice," Policy Sciences, vol. 35, no. 3, pp. 269-284, 2002.

[20] International Association of Oil \& Gas Producers, "Risk assessment data directory: vulnerability of humans," Tech. Rep. 434 $-14.1,2010$.

[21] R. K. Ahuja, T. L. Magnanti, and J. B. Orlin, Network Flows: Theory, Algorithms and Application, Pearson Education, New York, NY, USA, 1993.

[22] B.-C. Seet, G. Liu, B.-S. Lee, C.-H. Foh, K.-J. Wong, and K.-K. Lee, "A-STAR: a mobile ad hoc routing strategy for metropolis vehicular communications," in Networking 2004, vol. 3042 of Lecture Notes in Computer Science, pp. 989-999, Springer, Berlin, Germany, 2004.

[23] A. Stentz, "Optimal and efficient path planning for partiallyknown environments," in Proceedings of the IEEE International Conference on Robotics and Automation, pp. 3310-3317, May 1994.

[24] A. Stentz, "The focussed D* algorithm for real-time replanning," in Proceedings of the 14th International Joint Conference on Artificial Intelligence (IJCAI '95), vol. 2, pp. 1652-1659, 1995.

[25] R. T. Marler and J. S. Arora, "The weighted sum method for multi-objective optimization: new insights," Structural and Multidisciplinary Optimization, vol. 41, no. 6, pp. 853-862, 2010.

[26] R. T. Marler and J. S. Arora, "Survey of multi-objective optimization methods for engineering," Structural and Multidisciplinary Optimization, vol. 26, no. 6, pp. 369-395, 2004. 
[27] L. Zadeh, "Optimality and non-scalar-valued performance criteria," IEEE Transactions on Automatic Control, vol. 8, no. 1, pp. 59-60, 1963.

[28] K. Ghoseiri and B. Nadjari, "An ant colony optimization algorithm for the bi-objective shortest path problem," Applied Soft Computing Journal, vol. 10, no. 4, pp. 1237-1246, 2010. 


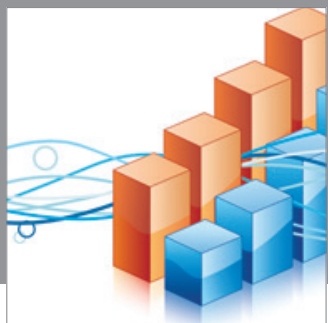

Advances in

Operations Research

mansans

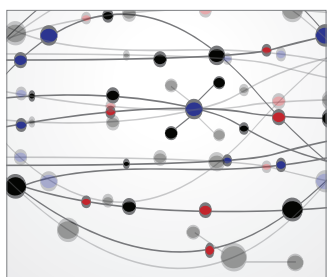

The Scientific World Journal
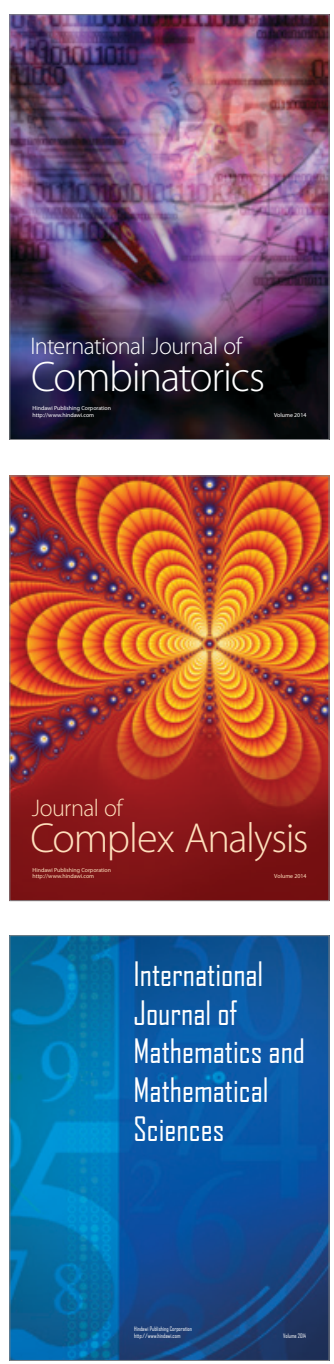
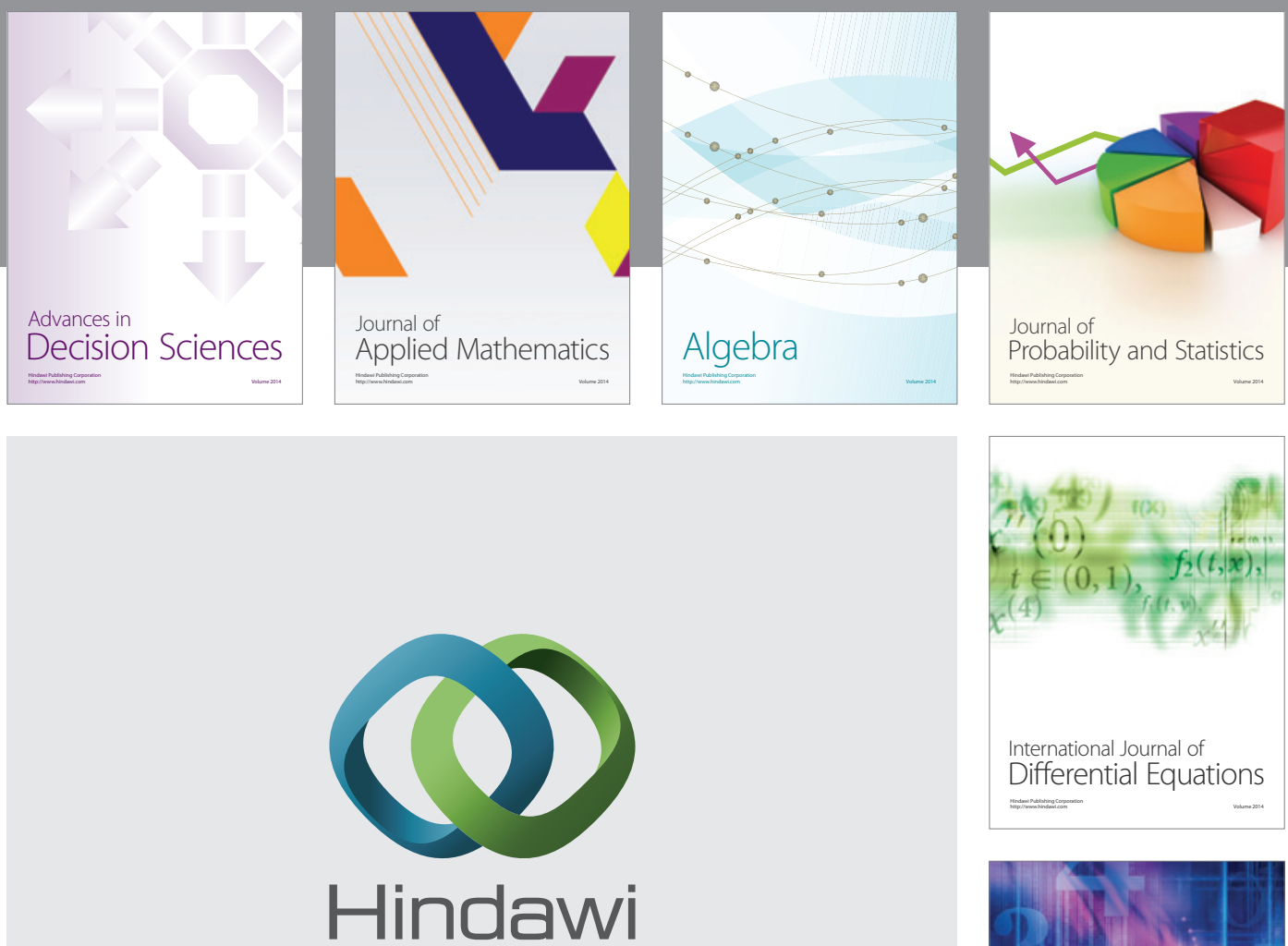

Submit your manuscripts at http://www.hindawi.com
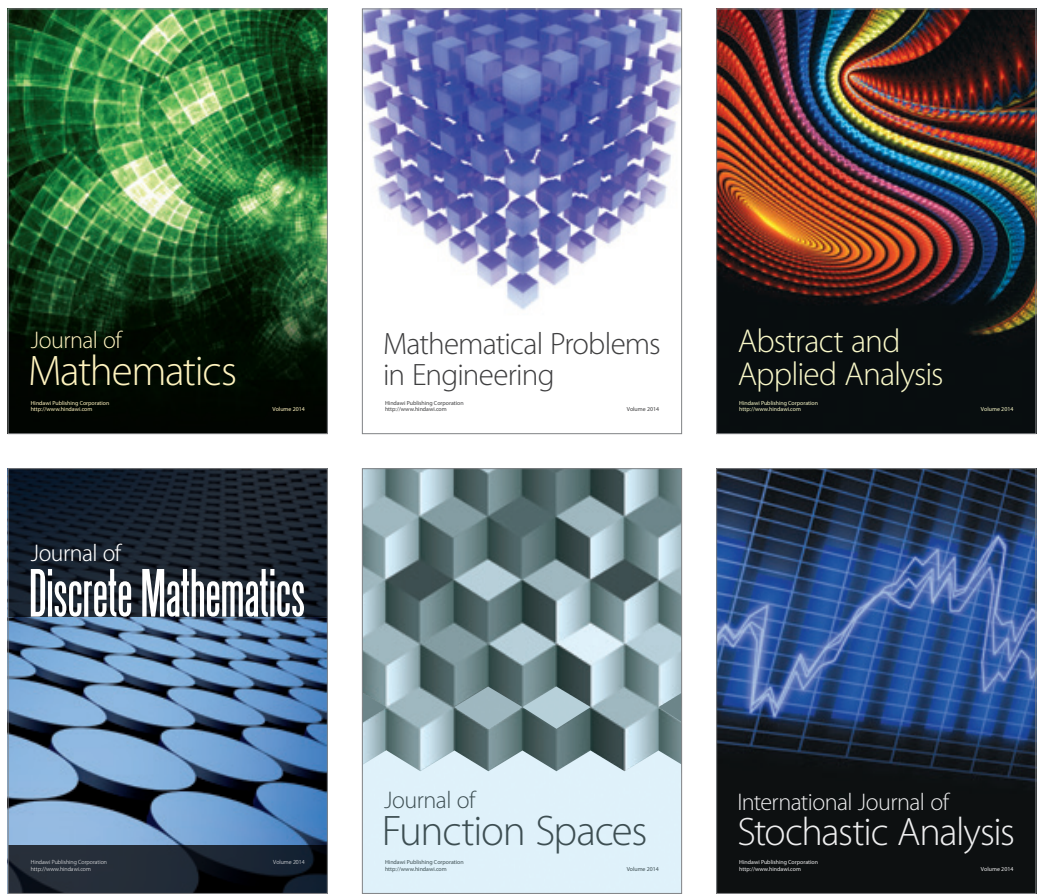

Journal of

Function Spaces

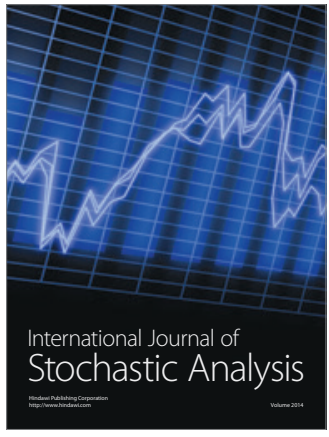

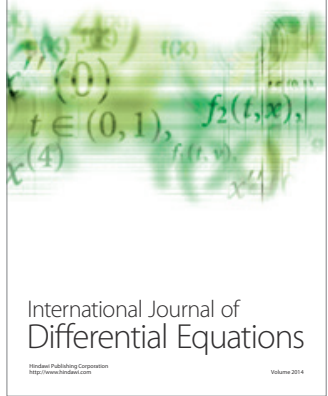
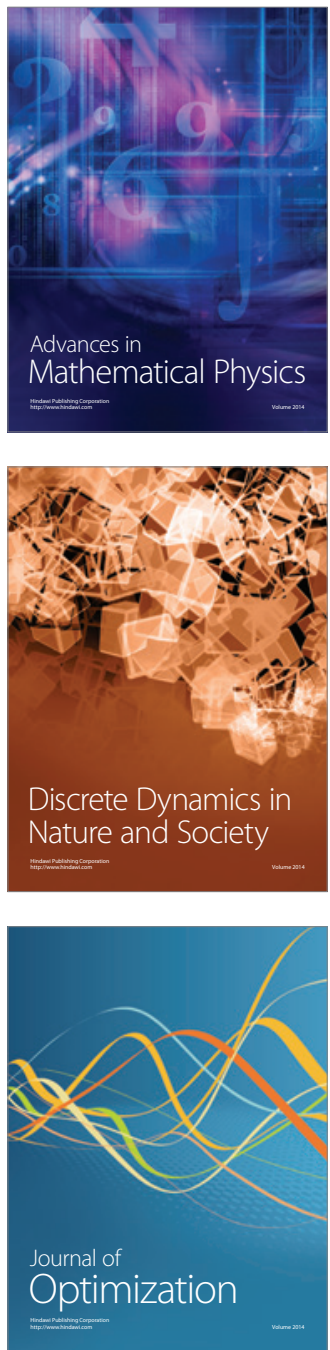